\title{
MODELING AND ANALYSIS OF LOW HEAT FLUX NATURAL CONVECTION SODIUM BOILING IN LMFBRS
}

Mohsen Khatib-Rahbar and Erik G. Cazzoli

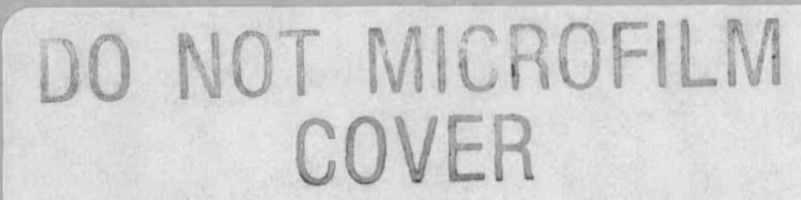

DATE PUBLISHED — SEPTEMBER 1982

CODE DEVELOPMENT, VALIDATION AND APPLICATION GROUP DEPARTMENT OF NUCLEAR ENERGY BROOKHAVEN NATIONAL LABORATORY UPTON, LONG ISLAND, NEW YORK 11973 


\section{DISCLAIMER}

This report was prepared as an account of work sponsored by an agency of the United States Government. Neither the United States Government nor any agency Thereof, nor any of their employees, makes any warranty, express or implied, or assumes any legal liability or responsibility for the accuracy, completeness, or usefulness of any information, apparatus, product, or process disclosed, or represents that its use would not infringe privately owned rights. Reference herein to any specific commercial product, process, or service by trade name, trademark, manufacturer, or otherwise does not necessarily constitute or imply its endorsement, recommendation, or favoring by the United States Government or any agency thereof. The views and opinions of authors expressed herein do not necessarily state or reflect those of the United States Government or any agency thereof. 


\section{DISCLAIMER}

Portions of this document may be illegible in electronic image products. Images are produced from the best available original document. 

This report was prepared as an account of work sponsored by an agency of the United States Government. Neither the United States Government nor any agency thereof, nor any of their employees, makes any warranty, express or implied, or assumes any legal liability or responsibility for the accuracy, completeness, or usefulness of any information, apparatus, product, or process disclosed, or represents that its use would not infringe privately owned rights. Reference herein to any specific commercial product, process, or service by trade name, trademark, manufacturer, or otherwise does not necessarily constitute or imply its endorsement, recommendation, or favoring by the United States Government or any agency thereof. The views and opinions of authors expressed herein do not necessarily state or reflect those of the United States Government or any agency thereof.

\title{
MODELING AND ANALYSIS OF LOW HEAT FLUX NATURAL CONVECTION SODIUM BOILING IN LMFBRS
}

\author{
Mohsen Khatib-Rahbar and Erik G. Cazzoli
}

NUREG / CR--2006

TI83 010683

\section{MANUSCRIPT COMPLETED — MARCH 1982 DATE PUBLISHED — SEPTEMBER 1982}

\author{
CODE DEVELOPMENT, VALIDATION AND APPLICATION GROUP \\ DEPARTMENT OF NUCLEAR ENERGY \\ BROOKHAVEN NATIONAL LABORATORY \\ UPTON, LONG ISLAND, NEW YORK 11973
}

Prepared for

\section{UNITED STATES NUCLEAR REGULATORY COMMISSION WASHINGTON, D.C. 20555




\section{DISCLAIMER}

This report was prepared as an account of work sponsored by an agency of the United States Government Neither the Untted States Government nor any agency thereof, nor any of their employees, nor any of their contractors, subcontractors, or their employees, makes any warranty, express or implied, or assumes any legal liability or responsibility for the accuracy, completeness, or usefulness of any information, apparatus, product, or process disclosed, or represents that its use would not infringe privately owned rights Reference herein to any specific commercial product, process, or service by trade name, trademark, manufacturer, or otherwise, does not necessarily constitute or imply its endorsement, recommendation, or favoring by the United States Government or any agency, contractor or subcontractor thereof The views and opinions of authors expressed herein do not necessarily state or reflect those of the United States Government or any agency, contractor or subcontractor thereof

Printed in the United States of America Avarlable from

National Technical Information Service

U S Department of Commerce 5285 Port Royal Road Springfield, VA 22161

NTIS price codes

Printed Copy A04, Microfıche Copy A01 


\begin{abstract}
Flow excursion induced dryout at low heat flux natural convection boiling, typical of liquid metal fast breeder reactor, is addressed. Steady state calculations indicate that low quality boiling is possible up to the point of Ledinegg instability leading to flow excursion and subsequent dryout in agreement with experimental data. A flow regimedependent dryout heat flux relationship based upon saturated boiling criterion is also presented. Transient analysis indicates that premature flow excursion can not be ruled out and sodium boiling is highly transient dependent. Analysis of a high heat flux forced convection, loss-of-flow transient shows a significantly faster flow excursion leading to dryout in excellent agreement with parallel calculations using the two-dimensional THORAX code.
\end{abstract}


. 
PAGE

ABSTRACT ........................

LIST OF TABLES ................................. vii

LIST OF FIGURES ................................

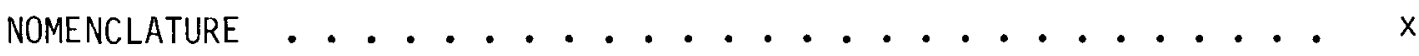

ACKNOWLEDGEMENT ..............................

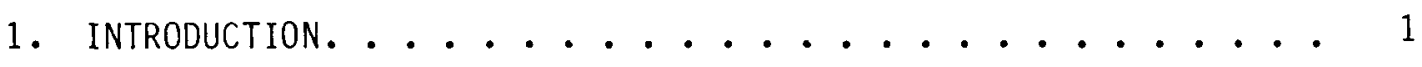

2. SODIUM BOILING AND FLOW EXCURSION PHENOMENON $\ldots \ldots . \ldots 3$

2.1 Steady State Equations ............ 5

2.2 Steady State Operational Regimes .......... 8

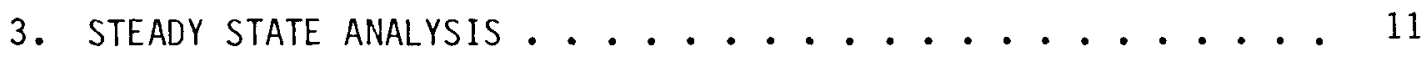

3.1 Clinch River Breeder Reactor Fuel Assembly . . . . . 11

3.2 Sodium Boiling Test Facility ........... 14

3.3 Dryout Criterion .................... 19

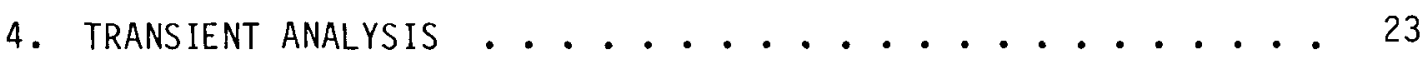

4.1 Conservation Equations ............. 23

4.2 Model Approximations ............. 24

4.3 Numerical Integration and SSC Interface ...... 27

4.3.1 Numerical Integration .......... 27

4.3 .2 SSC Interface .................. 28

4.4 Low Heat Flux Natural Convection Transients ...... 30

4.4 .1 Single Phase Flow ............ 30

4.4 .2 Two-Phase Flow ............. 30

4.5 High Heat Flux Boiling ............. 37

4.6 Comparison of Steady State and Transient Analysis . . . 39

5. SUMMARY AND CONCLUSIONS ................... 41 
CONTENTS (Cont.)

PAGE

REFERENCES ....................... 42

APPENDIX I - DEFINITION OF AVERAGE DENSITY ...... 45

APPENDIX II - FRICTION FACTOR CORRELATIONS . . . . 47

APPENDIX III - SINGLE PHASE NATURAL CONVECTION SOLUTION $\ldots 49$

APPENDIX IV - DERIVATION OF DRYOUT HEAT FLUX RELATION $\cdots 51$

APPENDIX $V$ - DRYOUT HEAT FLUX CALCULATIONS $\ldots \ldots . \ldots 52$ 
LIST OF TABLES

$\underline{T A B L E}$

I

II

II I

IV

V

VI
TITLE

Geometric Characteristics of CRBR Fuel Assembly . . . 11

Geometric Characteristics of SBT Facility . . . . . 17

SBT Natural Convection Test Results . . . . . . 20

Comparison of Heat Flux Limits . . . . . . . 21

Dryout Limits for MONJU Fuel Assembly . . . . . . . 21

Comparison of Quasi-Steady and Transient Analysis ... 39

- vii - 


\section{LIST OF FIGURES}

FIGURE

IITLE

PAGE

Pressure Drop Characteristics of (a) Low Pressure, and (b) High Pressure Systems During Flow Boiling.... . 4

2-2 Illustration of Low Pressure Natural Convection

Boiling Characteristics ............. 6

3-1 Pressure Drop Characteristics of an LMFBR Fuel

Assembly During Natural Convection Boiling . . . . 12

3-2 CRBR Fuel Assembly Pressure Drop versus Flow at

Various Power Densities $\left(T_{i}=673 \mathrm{~K}\right) \ldots . . . . . . .13$

3-3 Boiling Map for CRBR Fuel Assembly at Inlet

Temperature of $673 \mathrm{~K}$.............. 13

3-4 CRBR Fuel Assembly Pressure Drop versus Flow at

Various Power Densities $\left(T_{i}=873 \mathrm{~K}\right)$. . . . . . . 15

3-5 Boiling Map for CRBR Fuel Assembly at Inlet

Temperature of $873 \mathrm{~K}$. . . . . . . . . . . 15

3-6 Boiling Map for CRBRP Fuel Assembly at Inlet

Temperature of $1073 \mathrm{~K}$. . . . . . . . . 16

3-7 SBT Pressure Drop versus Flow at Various Power

Densities . . . . . . . . . . . . . 18

3-8 Boiling Map for ORNL Sodium Boiling Test Facility . • • 18

4-1 Schematics of a Boiling Channel During a Transient . • . 25

4-2 Flow Chart for SSC . . . . . . . . . . 29

4-3 Flow Response versus Time .............. 31

4-4 Coolant Temperatures . . . . . . . . . 31

4-5 Reactor Inlet and Outlet Pressures . . . . . . . 31

4-6 Coolant Temperatures ........................ 33

4-7 Axial Position of the Boiling Region ............ 33

4-8 Subassembly Average Flow Rate . . . . . . . . 34 


\section{LIST OF FIGURES}

FIGURE

TITLE

PAGE

4-9

Subassembly Inlet and Outlet Flow Rates . . . . . . 34

4-10

Subassembly Average Flow Rate . . . . . . . . . 35

$4-11$

Axial Position of the Voided Region . . . . . . . 35

$4-12$

Coolant Temperature . . . . . . . . . . 36

$4-13$

Void Fraction at the Subassembly Exit . . . . . . 36

$4-14$

Axial Position of the Two-Phase Region Following

Boiling Inception . . . . . . . . . . . . 38

4-15 Subassembly Inlet Flow Rate Following Boiling

Inception . . . . . . . . . . . . . 38 


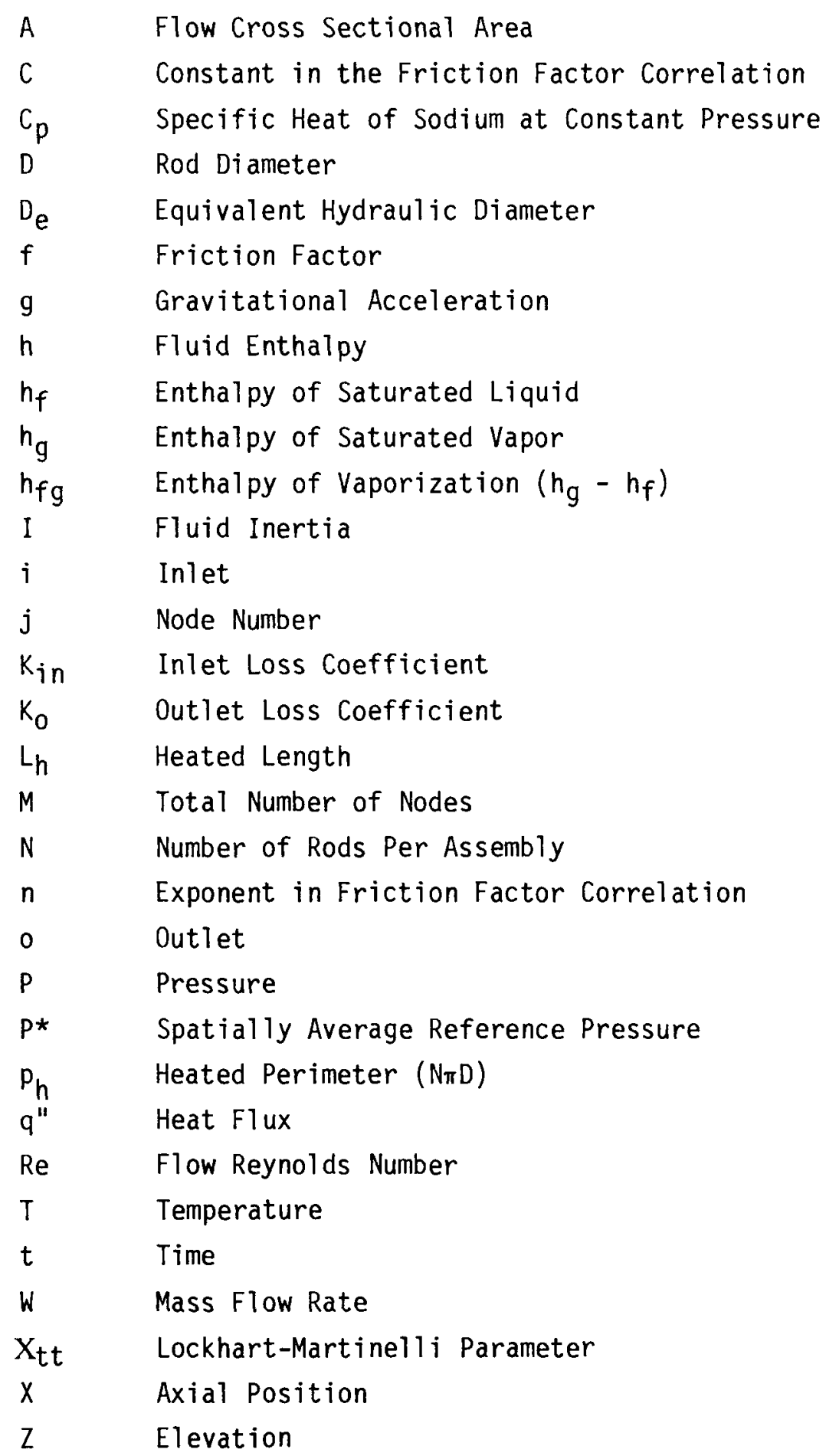


GREEK SYMBOLS

$\begin{array}{ll}\alpha & \text { Void Fraction } \\ B & \text { Volume Coefficient of Thermal Expansion } \\ \Delta h_{S C} & \text { Inlet Subcooling }\left(h_{f}-h\right) \\ \Delta T_{S C} & \text { Inlet Subcooling }\left(T_{f}-T\right) \\ \xi & \text { Ledinegg Stability Parameter } \\ \langle\rho\rangle & \text { Average Density } \\ \rho_{f} & \text { Density of Saturated Liquid } \\ \rho_{g} & \text { Density of Saturated Vapor } \\ \rho_{0} & \text { Reference Liquid Density } \\ \nu_{f} & \text { Specific Volume of Saturated Liquid } \\ \nu_{g} & \text { Specific Volume of Saturated Vapor } \\ \nu_{f g} & \left.\text { ( } \nu_{f}-\nu_{g}\right) \\ \mu_{f} & \text { Dynamic Viscosity of Saturated Liquid } \\ \mu_{g} & \text { Dynamic Viscosity of Saturated Vapor } \\ \mu_{f g} & \left.\text { ( } \mu_{f}-\mu_{g}\right) \\ x & \text { Quality }\end{array}$




\section{ACKNOWLEDGMENT}

The authors wish to extend their appreciation to Professor John E. Meyer of the Massachussetts Institute of Technology for numerous technical discussions and his valuable advice throughout this study.

Thanks are due to Dr. Akira Watanabe and Mr. Nobuo Tanaka of the Power Nuclear and Fuel Development Corporation (PNC) of Japan for providing partial financial support of this project, to Drs. J. G. Guppy and R. J. Cerbone for reviewing, and to Mrs. Carmen Falkenbach for typing the manuscript.

The work reported here was also supported in part by the Division of ACcident Evaluation, United States Nuclear Regulatory Commission. 


\section{INTRODUCTION}

The Liquid Metal Cooled Fast Breeder Reactors (LMFBR's) are currently designed so that the maximum coolant temperature during normal operation is about $350^{\circ} \mathrm{K}$ below the saturation temperature. Nevertheless, despite this large temperature margin, hypothetical accidents must be envisioned that would lead to coolant temperature excursions and boiling.

Among the most serious of the postulated accidents are the primary lossof-piping integrity accident and the complete loss-of-heat sink accident. Analysis models used to calculate the consequences of such accidents assume that once sodium boiling is initiated film dryout occurs as a result of rapid vapor bubble growth and subsequent subassembly flow stagnation or reversal.

There are many factors, such as transient flow redistribution between subassemblies, that will determine whether flow stagnation and boiling will occur in a particular subassembly in a particular accident [1]. Once boiling is initiated in an assembly, a substantial gravity pressure difference would exist between this assembly and other cooler assemblies in the core, giving rise to natural convection flow boiling accompanied by flow oscillations prior to dryout.

During the past several years a number of experiments have been performed to determine the physical behavior of sodium boiling. Ford [2] used Freon-113 in vapor slug-expulsion experiments to develop a model which became the basis for early versions of the SAS computer code [3]. Hinkle [4] used a low pressure water loop to simulate sodium boiling behavior under natural circulation conditions. This work served as the basis for the sodium boiling experiments at $\mathrm{ORNL}$ by Garrison, et. al. [5]. More recently other experiments with both sodium [6] and water [7] have been performed at ORNL and MIT respectively.

of particular interest to LMFBR safety analysis, is the prediction of sodium boiling behavior and conditions conducive to the fuel pin dryout phenomenon.

Analytical models to date are based on the slug flow approximations similar to that employed by the SAS computer code [3]. SAS was originally developed to describe sodium boiling behavior under conditions of high heat flux, (normally of short transient duration) typical of unprotected transient overpower (TOP) and loss of flow (LOF) accidents. Furthermore, application of the SAS type model has been shown [8] to be very sensitive to a number of user supplied parameters such as, liquid film thickness at the time of voiding inception; degree of superheat and wall friction factor. For example better results are obtained when a single-phase vapor friction factor is used during boiling which is highly contradictory to the slug-annular flow regime assumption of the model. Another important consideration is the numerical efficiency and machine time requirements, which can be excessive for events of long duration typical of protected transients.

Detailed multidimensional boiling models have also been developed and used to study sodium boiling phenomenon in LMFBR rod bundles $[9,10]$; however, due to the mathematical and numerical complexity of these methods, their application to long duration natural convection transients is not very practical. 
It is therefore, the principal objective of the present work to formulate a practical predictive method for analysis of low heat flux sodium boiling during natural convection transient events in LMFBRs.

Section 2 examines the physical processes responsible for two-phase instability effects leading to flow excursion and subsequent fuel pin dryout. An approximate dryout heat flux criterion is also presented.

Ledinegg's phenomenon is further demonstrated in Section 3 through steady state analysis of a Clinch River Breeder Reactor (CRBR) fuel assembly and the Oak Ridge National Laboratory (ORNL) Sodium Boiling Tests (SBT). Impact of various parameters on two-phase flow behavior is discussed, and the approximate dryout criterion is also examined.

Section 4 describes the transient model equations and their relation to the SSC in-core thermal hydraulic calculations. The transient model is used to study sodium boiling characteristics for a loss-of-electric power (LOEP) transient leading to natural circulation in CRBR. Furthermore, the model is also applied to a high heat flux loss-of-flow transient and the results are compared to parallel two-dimensional calculations using the THORAX code.

Section 5 summarizes the study and identifies limitations of the steady and transient calculations and the need for experimentation and validation. 


\section{SODIUM BOILING AND FLOW EXCURSION PHENOMENON}

The low pressure operation of sodium cooled fast reactors compared with light water reactors influences the overall pressure drop characteristic during boiling. With a high pressure system it is possible to have a single valued pressure drop-fl ow characteristic for a boiling channel, but with low pressure systems this is not so.

Figure 2-1 illustrates the difference between low and high pressure boiling systems. It is seen for the low pressure system that the flow rate can be multi-valued for certain available pressure characteristics. The increase of the pressure drop as the flow is reduced to cause boiling is due to an increase in the frictional component and the requirement of extra pressure head to produce the necessary acceleration from the single-phase fluid to a twophase mixture. Both these terms decrease as the system pressure increases, and consequently at a sufficiently higher pressure there is no increase in the pressure drop as the flow is reduced to produce boiling [11].

For low pressure sodium boiling, the implications of the S-curve shown in Fig. 2-1a are that at the onset of boiling a flow excursion could take place and possibly cause the Critical Heat Flux (CHF) conditions to be exceeded.

The flow excursion instability al so referred to as Ledinegg instability $[12,13]$ can be explained using a simple momentum balance equation of the form:

$$
I \frac{d W}{d t}=(\Delta P)_{E X T}-(\Delta P)_{\text {int }}
$$

where $W$ is the coolant mass flow rate, I is the fluid inertia $(L / A),(\Delta P)_{\text {int }}$ is the channel internal pressure drop due to friction, spatial acceleration, buoyancy, inlet and outlet orifices, and $(\Delta P)_{E X T}$ is the driving pressure differential.

For a small perturbation around an equilibrium point $W_{0}$,

$$
\begin{gathered}
W=W_{0}+\delta W \\
(\Delta P)_{\text {int }}=\left[(\Delta P)_{\text {int }}\right]_{W_{0}}+\frac{\partial}{\partial W}\left[(\Delta P)_{\text {int }}\right]_{W_{0}} \delta W \\
(\Delta P)_{E X T}=\left[(\Delta P)_{E X T}\right]_{W_{0}}+\frac{\partial}{\partial W}\left[(\Delta P)_{E X T}\right]_{W_{0}} \delta W
\end{gathered}
$$

The following solution for the flow perturbation can be obtained:

$$
\delta W=\delta W_{0} \exp (\xi t / I)
$$



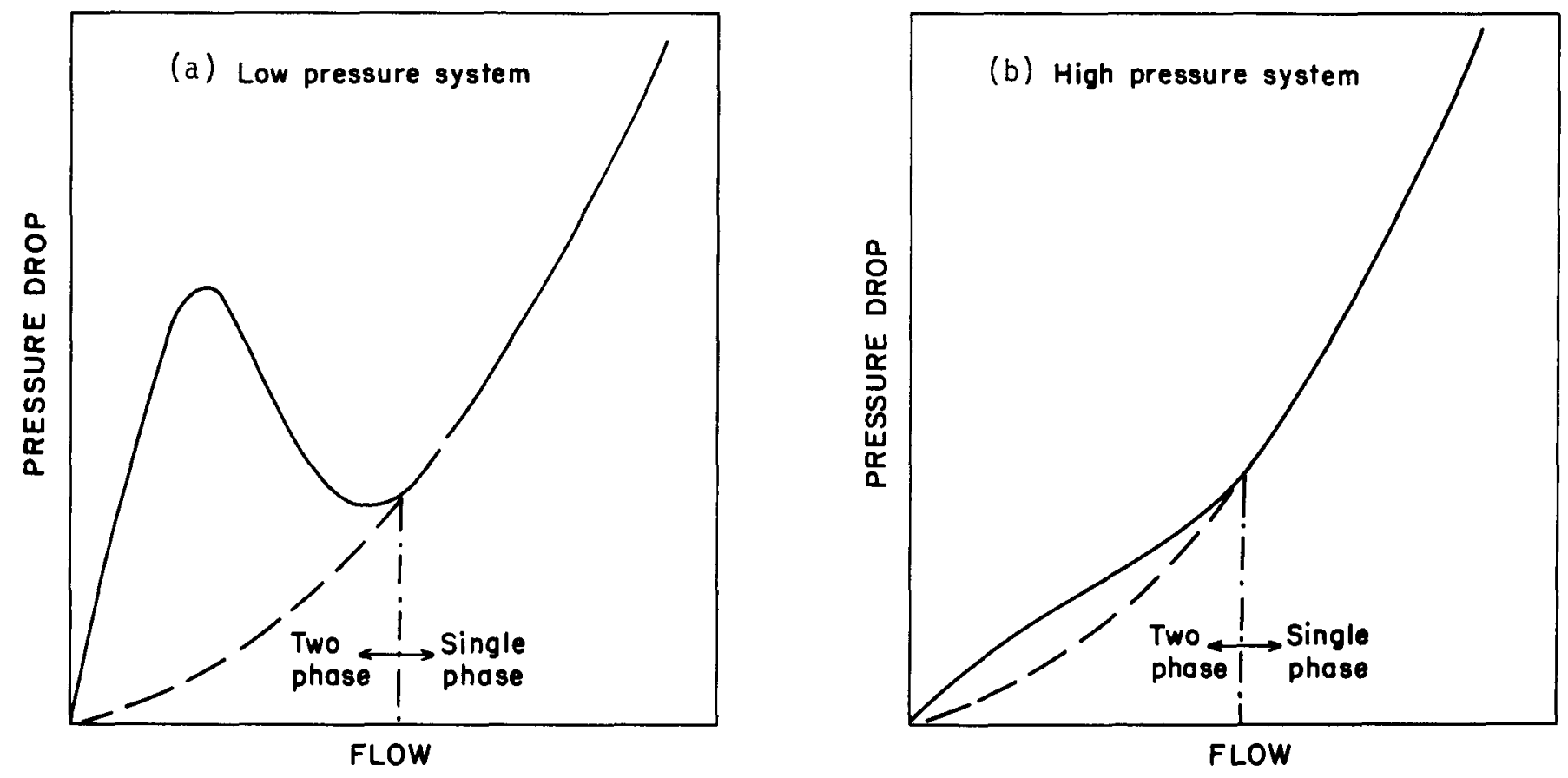

Figure 2-1 Pressure Drop Characteristics of (a) Low Pressure, and (b) High Pressure Systems During Flow Boiling 
where

$$
\xi=\left[\begin{array}{lll}
\frac{\partial}{\partial W} & (\Delta P)_{E X T}-\frac{\partial}{\partial W}(\Delta P)_{\text {int }}
\end{array}\right]_{W_{0}}
$$

Equation (2-3) shows that the perturbation $\delta W_{0}$ will grow if $\xi$ is positive. In other words the system will be unstable if the slope of the internal pressure drop is more negative than the slope of the external pressure differential. For natural convection boiling, the slope of the external pressure drop is zero, hence, instabilities can occur for any negative slope of the internal characteristic.

Equation (2-3) shows that the flow excursion process is a transient phenomenon and its time constant is directly related to the fluid inertia and pressure drop characteristics. At natural convection boiling conditions the value of $\xi$ increases with increasing heat flux; and therefore the flow excursion process will take place over a much shorter duration at higher heat flux levels, as demonstrated later in this report.

The time-dependent momentum equation was used to derive the stability criterion of equation (2-4), however, the criterion itself (negative value of $\xi$ ) is based on steady-state considerations only.

Figure 2-2a shows typical pressure-drop versus flow rate and heat flux characteristics for sodium under natural convection conditions. The intersections of these curves with the external pressure differential \#PEXT (horizontal line) represent possible operating conditions.

Figure 2-2b illustrates all possible solutions in terms of mass flow rate and heat flux. The dashed line indicates the unstable operating points while the solid lines show the stable conditions. It is therefore evident that for certain values of heat flux, multiple solutions exist for the mass flow rate and thus the operating condition is highly dependent on the past history.

\subsection{Steady State Equations}

Steady state single-phase and two-phase natural convection behavior of channel flows can be examined through solution of the steady state energy and momentum equations of the form:

$$
h_{j}=h_{j-1}+\frac{N_{\pi} D \Delta X_{j q}{ }_{j}}{W} \quad j=2,3, \ldots, M
$$

and

$$
\begin{aligned}
\Delta P= & \frac{1}{2}\left(\frac{W}{A}\right)^{2}\left\{\sum_{j=2}^{M}\left[\frac{\phi_{j} f_{j} \Delta x_{j}}{D_{e} \rho_{f}}\right]+\left[\frac{\left(1-x_{0}\right)^{2}}{\rho_{f}\left(1-\alpha_{0}\right)}+\frac{x_{0}^{2}}{\rho_{g} \alpha_{0}}-\frac{1}{\rho_{i}}\right]\right. \\
& \left.+\left[\frac{K_{i n}}{\rho_{i}}+\frac{K_{0} \phi_{0}}{\rho_{f}}\right]\right\}+g \sum_{j=2}^{M}<\rho_{j}>\Delta z_{j}
\end{aligned}
$$




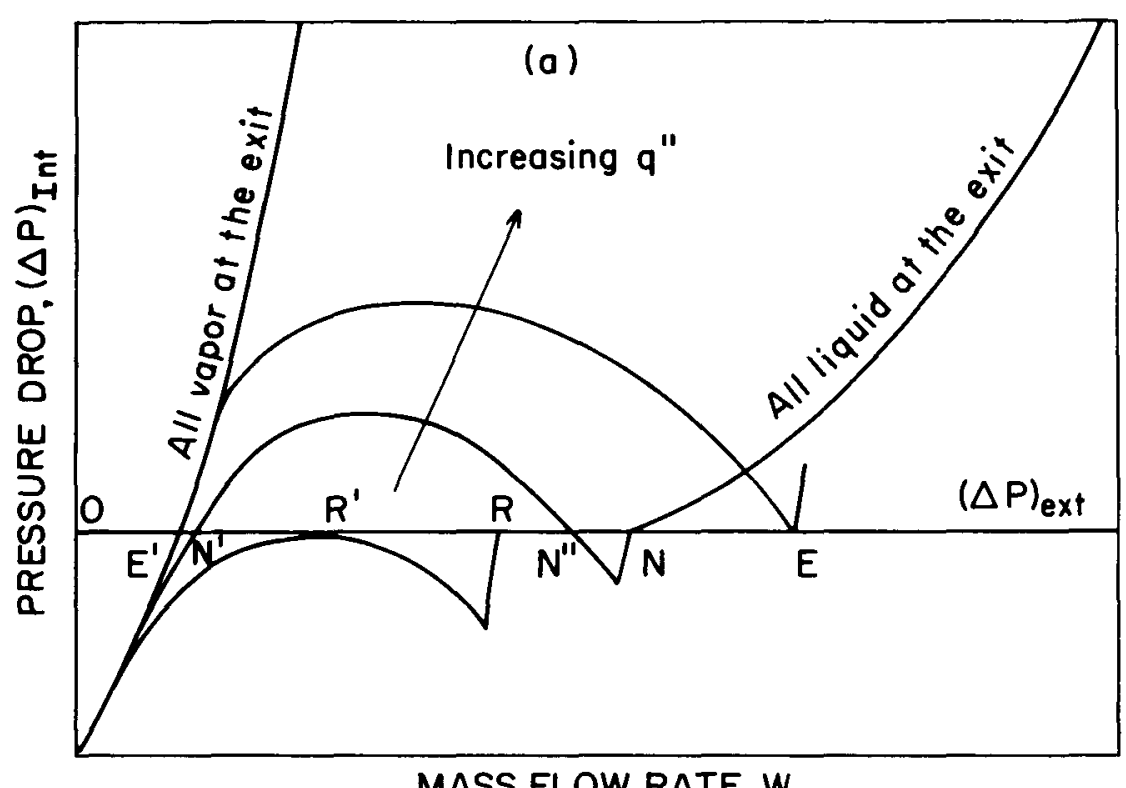

MASS FLOW RATE, W

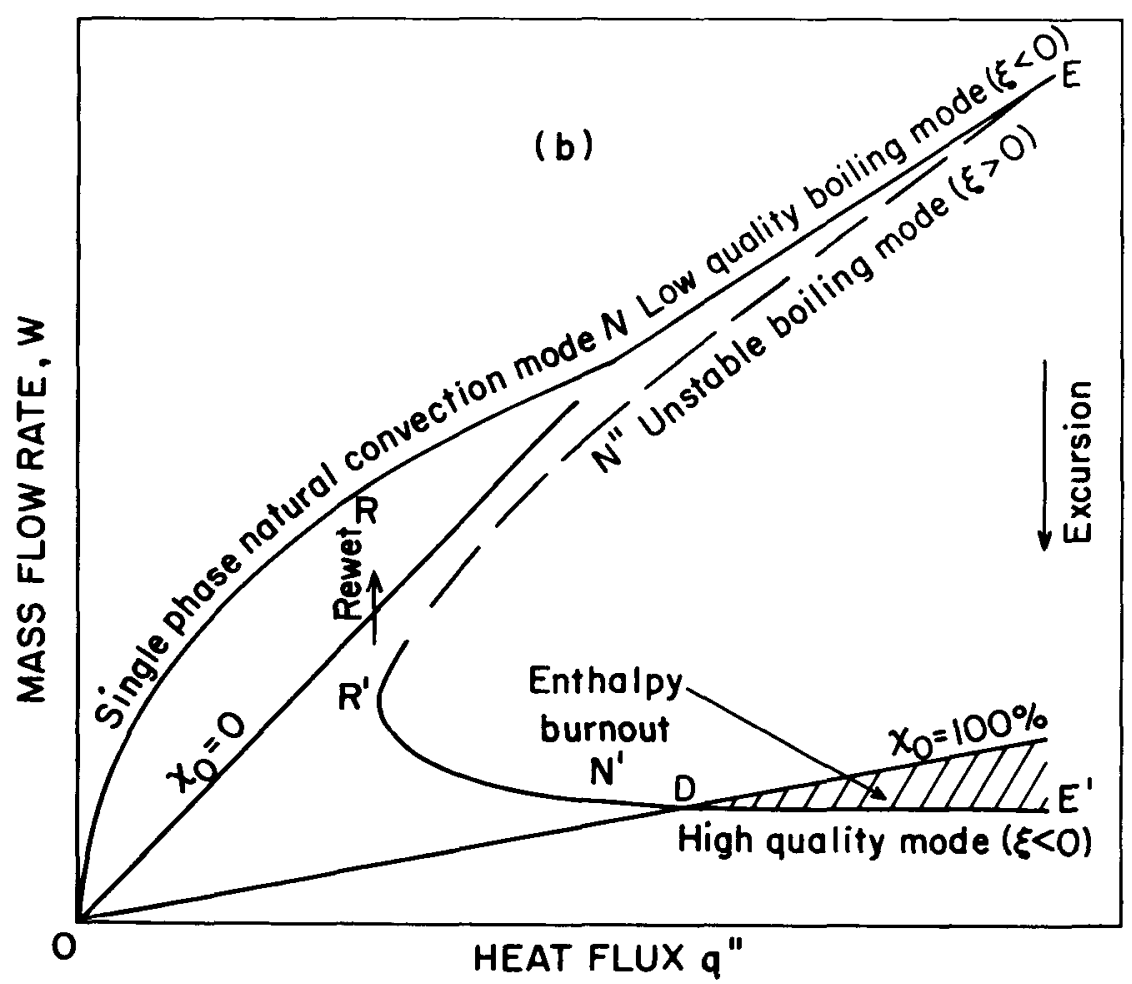

Figure 2-2 Illustration of Low Pressure Natural Convection Boiling Characteristics 

[14]:

The two-phase flow multiplier can be defined by the homogeneous equation

$$
\begin{aligned}
& \phi_{j}=\left(1-x_{j} \frac{v_{f g}}{v_{f}}\right)\left(1+x_{j} \frac{\mu_{f g}}{\mu_{g}}\right)^{-0.25} \\
& \phi_{0}=\left(1+\frac{v_{f g}}{v_{f}} x_{0}^{1.5}\right)
\end{aligned}
$$

The void fraction, $\alpha$ is determined using the following relation [15]:

$$
\alpha=\frac{1}{1+0.28 x_{t t}^{0.71}}
$$

where the two-phase flow modulus also known as the Lockhart-Martinelli parameter is defined as:

$$
X_{t t}=\left(\frac{1-x}{x}\right)^{0.9}\left(\frac{\rho_{g}}{\rho_{f}}\right)^{0.5}\left(\frac{\mu_{f}}{\mu_{g}}\right)^{0.1}
$$

The Lockhart-Martinelli void fraction relation, approximated by equation (2-8) has been found to be in excellent agreement with the recent liquid metal test data as discussed by costa[16].

The nodal average density, $\left\langle\rho_{j}\right\rangle$ is defined in Appendix I.

The single-phase friction factor is defined by:

$$
f=C R e^{-n}
$$

where $n=1$ for laminar flow and $n=0.25$ for turbulent flow.

For laminar flow through wire-wrapped fuel assemblies $C$ is measured to be constant and equal to 84 [17]. On the other hand for turbulent flow $\mathrm{C}$ is a complicated function of the pitch to diameter ratio and the spiral wire lead as correlated recently $[18,19]$ (see Appendix II).

For single-phase (subcooled or superheated) flow, equation (2-6), is appropriately modified by setting $\phi_{j}$, and $\phi_{0}$ to 1.0 and the density to its single phase value. 


\subsection{Steady State Operational Regimes}

The operational regimes identified in Fig. 2-2 illustrate that single phase natural convection flow exists along the curve $\mathrm{ON}$ and the flow rate and enthalpy rise can be derived (see Appendix III) by solving eqs. (2-5), (2-6) and (2-10) along with an equation of state for density to obtain [20]:

and

$$
W \sim q^{\prime \prime} 1 /(3-n)
$$

$$
\Delta h \sim q^{\prime \prime}(2-n) /(3-n)
$$

Equations (2-11) and (2-12) indicate the importance of the flow regime change during natural convection cooling, that is for laminar flow, both $W$ and $\Delta h$ are proportional to the $\sqrt{q^{\prime \prime}}$; while for turbulent flow $W \sim q^{10} 0.36$ and $\Delta h \sim$ $q^{\prime 0.64}$. Therefore it is essential to include the Reynolds number dependence for accurate prediction of natural convection behavior [20].

The boiling regimes identified on Fig. 2-2 consist of:

Low Quality Boiling Mode (Line NE) - The operating points on this line correspond to the stable $(\xi<0)$ low quality boiling regime. At $E$ boiling becomes unstable and flow excursion takes place.

Unstable Boiling Mode ( $R^{\prime} N^{\prime \prime} E$ ) - Operation along this curve is statically unstable $(\xi>0)$ and can lead to flow excursion. Also, due to the close proximity of the low quality boiling (Line NE) and the unstable boiling mode solutions, operation with boiling in this heat flux range is expected to be oscillatory in nature, and can often lead to premature excursion.

Stable High Quality Mode (R'N'D E') - Vapor quality along this path is high and the fluid approaches saturated vapor condition at $D$, at which point enthalpy burnout takes $\mathrm{place}$. Therefore, stable operation beyond $D$ is considered unsafe, and can cause fuel pin failure. Furthermore at $R^{\prime}$ the flow is unstable and can recover to high flow natural convection leading to restoration of single-phase flow.

Therefore, the heat flux corresponding to the intersection of the saturated vapor line $\left(x_{0}=100 \%\right)$ and the high quality curve is of special significance. An approximate analytical solution for this intersection can be found, assuming that the non-boiling length is much smaller than the total length (very small inlet subcooling). Solving the coolant momentum equation for the condition that exit quality is $100 \%$ and using an all vapor friction factor one obtains (see Appendix IV):

$$
W \simeq \rho_{g} A\left[\frac{2 g\left(\rho_{f}-\rho_{g}\right) D_{e}^{1+n}}{C \mu_{g} \rho_{g}{ }^{1-n}}\right]^{1 /(2-n)}
$$


In other words, in order to maintain a dried-out region in the upper part of the rod bundle, the vapor production rate in the lower part of the rod bundle must be sufficient to maintain voiding and thus prevent reentry of liquid for rewetting, and therefore, the heat flux corresponding to this vapor production rate is termed the "dryout heat flux" and is determined by substituting equation (2-13) into the energy equation to obtain:

$$
q_{\text {Dryout }} \geq\left[\frac{2 g \rho_{g}\left(\rho_{f}-\rho_{g}\right) D_{e}^{1+n}}{C \mu_{g}^{n}}\right]^{1 /(2-n)} \frac{A}{\pi N D L_{h}}\left(\Delta h_{s c}+h_{f g}\right)
$$

Again, the influence of flow regime is clearly evident. Equations (2-13) and (2-14) are similar to the reentry criterion proposed by Dunn [21] and later modified by Fauske and Ishii [22]. These equations treat the flow regime explicitly, and as such the vapor production rate and subsequently the heat flux does not depend on the magnitude of the Reynolds number, but only on its range (turbulent, transition or laminar).

The dryout heat flux approximated by Eq. (2-14) will be compared to the detailed numerical solution of the energy and momentum equations (Eqs. (2-5) through $(2-10)$ ) to assess its range of validity for low heat flux natural convection boiling. 


\section{STEADY STATE ANALYSIS}

The steady state model described in the previous section is used to study the sodium boiling characteristics of the Clinch River Breeder Reactor Plant (CRBRP) [23] fuel assemb1y, and the Oak Ridge National Laboratory Sodium Boiling Test (SBT) system[5].

\subsection{Clinch River Breeder Reactor Fuel Assembly}

The CRBRP fuel assemblies consist of 217 pins arranged in a triangular configuration as summarized in Table I. Figure 3-1 illustrates the steady state pressure drop versus flow rate characteristics at an average power density of $150 \mathrm{MW} / \mathrm{m}^{3}\left(4.87 \mathrm{kw} / \mathrm{pin}\right.$ or $\left.19.5 \mathrm{~W} / \mathrm{cm}^{2}\right)$. Al so shown is the importance of various components of the pressure drop. The S-shape behavior, typical of low pressure boiling discussed earlier, is clearly evident.

Figure 3-2 shows the pressure drop versus flow rate characteristics at various power densities. The intersection of these curves with the constant, convective driving head provide the possible operating conditions shown in Fig. 3-3.

Table I Geometric Characteristics of CRBR Fuel Assembiy

\begin{tabular}{|l|l|}
\hline Inlet Orifice Length, $m$ & 1.750 \\
Lower Axial Balnket Length, $m$ & 0.356 \\
Fuel Length, $m$ & 0.914 \\
Upper Axial Blanket Length, $m$ & 0.356 \\
Upper Fission Gas Plenum Length, $m$ & 1.219 \\
Outlet Orifice Length, $m$ & 0.876 \\
Hydraulic Area, ${ }^{2}$ & \\
Inlet & $2.552 \times 10^{-3}$ \\
Bundle & $4.335 \times 10^{-3}$ \\
Outlet & $4.335 \times 10^{-3}$ \\
Hydraulic Diameter, $m$ & 0.057 \\
Inlet & $3.25 \times 10^{-3}$ \\
Bundle & $3.25 \times 10^{-3}$ \\
Outlet & 2.70 \\
Inlet Loss Coefficient, $K_{i n}$ & 0.698 \\
Outlet Loss Coefficient, $K_{0}$ & \\
\hline
\end{tabular}




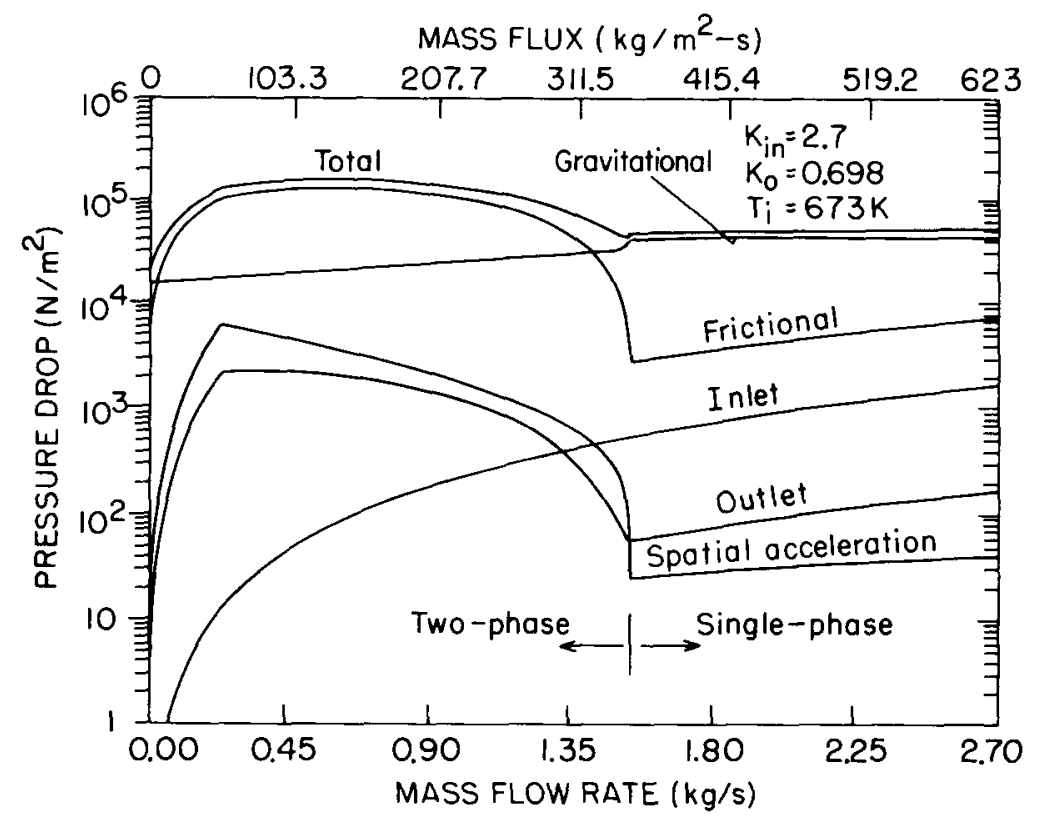

Figure 3-1 Pressure Drop Characteristics of an LMFBR Fuel Assembly During Natural Convection Boiling 


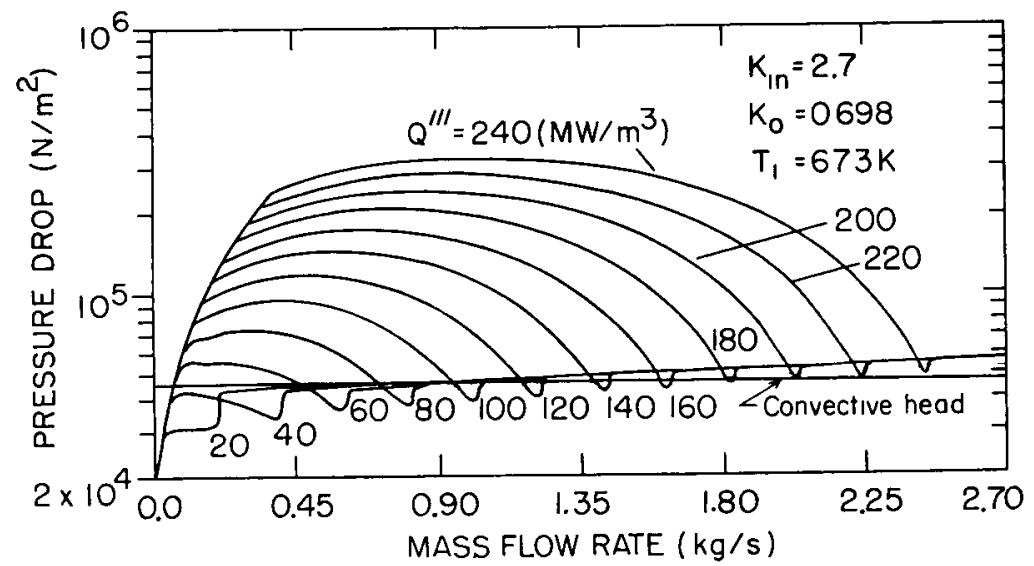

Figure 3-2 CRBR Fuel Assembly Pressure Drop versus Flow at Various Power Densities $\left(T_{j}=673 \mathrm{~K}\right)$

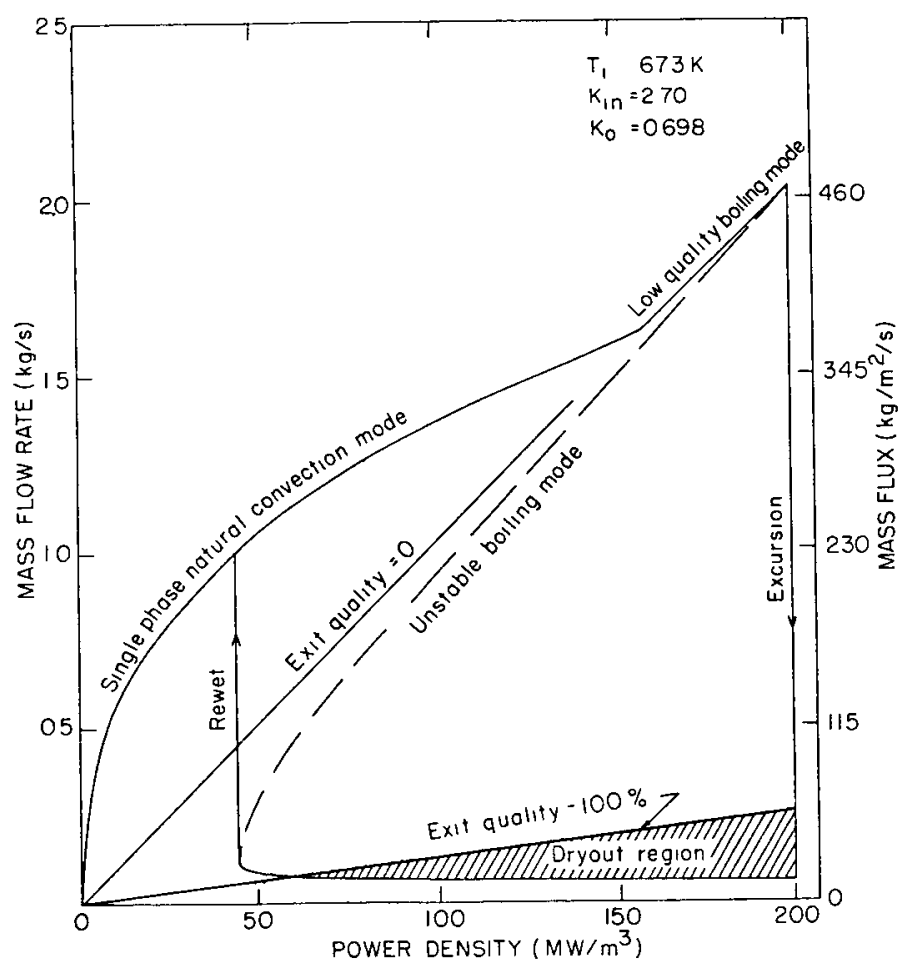

Figure 3-3 Boiling Map for CRBR Fuel Assembly at Inlet Temperature of $673 \mathrm{~K}$ 
Single-phase natural convection flow exists for steady power densities up to $160 \mathrm{MW} / \mathrm{m}^{3}(5.2 \mathrm{kw} / \mathrm{pin})$. Low quality stable boiling occurs for power densities greater than $160 \mathrm{MW} / \mathrm{m}^{3}$ up to the critical power density of $200 \mathrm{MW} / \mathrm{m}^{3}$ $\left(6.5 \mathrm{kw} / \mathrm{pin}\right.$ or $\left.26 \mathrm{~W} / \mathrm{cm}^{2}\right)$ beyond which, flow excursion leading to enthalpy burnout takes place. Recovering from high-quality low-flow condition is not possible until the power density is reduced to about $44 \mathrm{MW} / \mathrm{m}^{3}(1.43 \mathrm{kw} / \mathrm{pin})$.

Figure 3-3 also illustrates that the two-phase unstable mode solutions are very close to the stable low quality mode solutions; however, boiling is expected to take place as a result of different power and flow decay characteristics during transient operation. Furthermore premature flow excursions at power densities beyond $57 \mathrm{MW} / \mathrm{m}^{3}\left(1.83 \mathrm{kw} / \mathrm{pin}\right.$ or $\left.7.3 \mathrm{~W} / \mathrm{cm}^{2}\right)$ will lead to film dryout and subsequent cladding temperature excursions.

The boiling map exemplified by Fig. 3-3 demonstrates a very important characteristic, that, sodium boiling phenomenon is strongly path dependent. Let us consider a case where a system is operating at low power, single-phase natural convection; increasing the power level in small quasi-steady steps leads to an increase in the convective flow along the single-phase natural convection curve. However, if the power level is increased in a large step or ramp, the system can easily move to the right of the two-phase unstable operating curve and thus undergo a premature excursion. A similar situation arises during constant power, variable flow conditions, such as flow coastdown at decay power levels or protected loss-of-piping integrity accidents.

Factors influencing the system operating characteristics during boiling include inlet and outlet orifice losses, and the inlet subcooling.

An enlargement in inlet restriction increases single-phase flow friction and thus provides a damping effect which increases the system stability. A restriction at the exit of a boiling channel increases two-phase friction, which in turn reduces the system stability.

The impact of subassembly inlet subcooling is demonstrated in Figures 3-2 through 3-6. Higher sodium inlet temperature reduces the margin to boiling inception and this lowers the point of sodium flow excursion. However, the heat flux interval between the flow excursion and the rewetting process is reduced as the inlet temperature is increased. It must be noted that a significant increase in the subassembly inlet temperature can occur during loss-ofheat sink accidents.

\subsection{Sodium Boiling Test Facility}

A similar analysis is performed for the ORNL single-channel sodium boiling experiments.

The geometric characteristics of the SBT test section are approximately equal to those of a full scale LMFBR fuel assembly as listed in Table II [5]. It consists of a radiant furnace heater region, followed by the simulated fission gas plenum region downstream of the heated zone. 


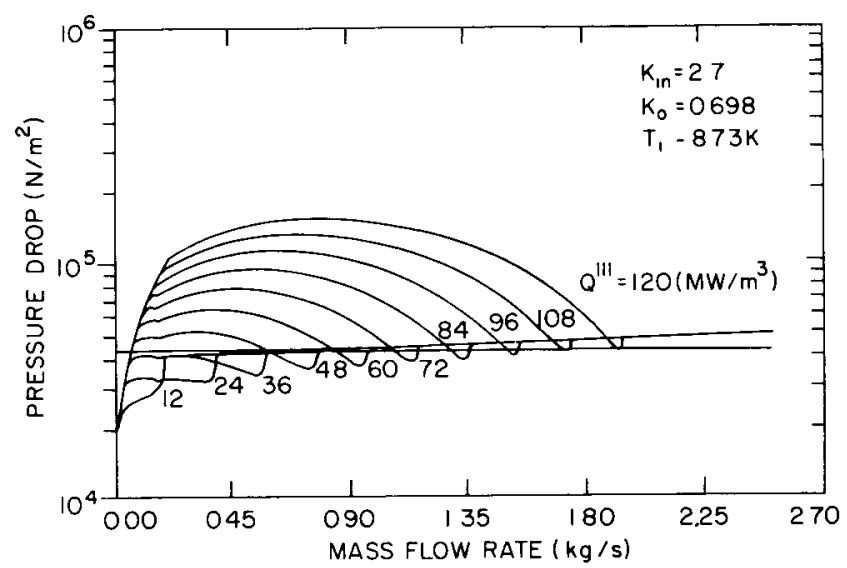

Figure 3-4 CRBR Fuel Assembly Pressure Drop versus Flow at Various Power Densities $\left(T_{\mathbf{i}}=873 \mathrm{~K}\right)$

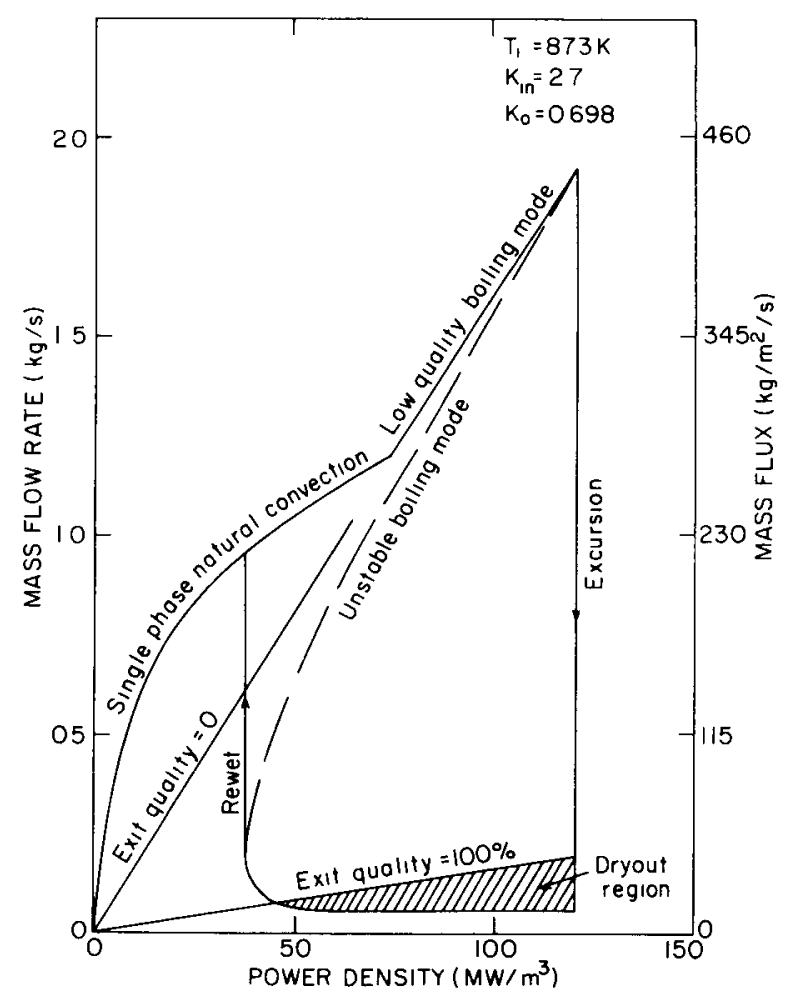

Figure 3-5 Boiling Map for CRBR Fuel Assembly at Inlet Temperature of $873 \mathrm{~K}$ 


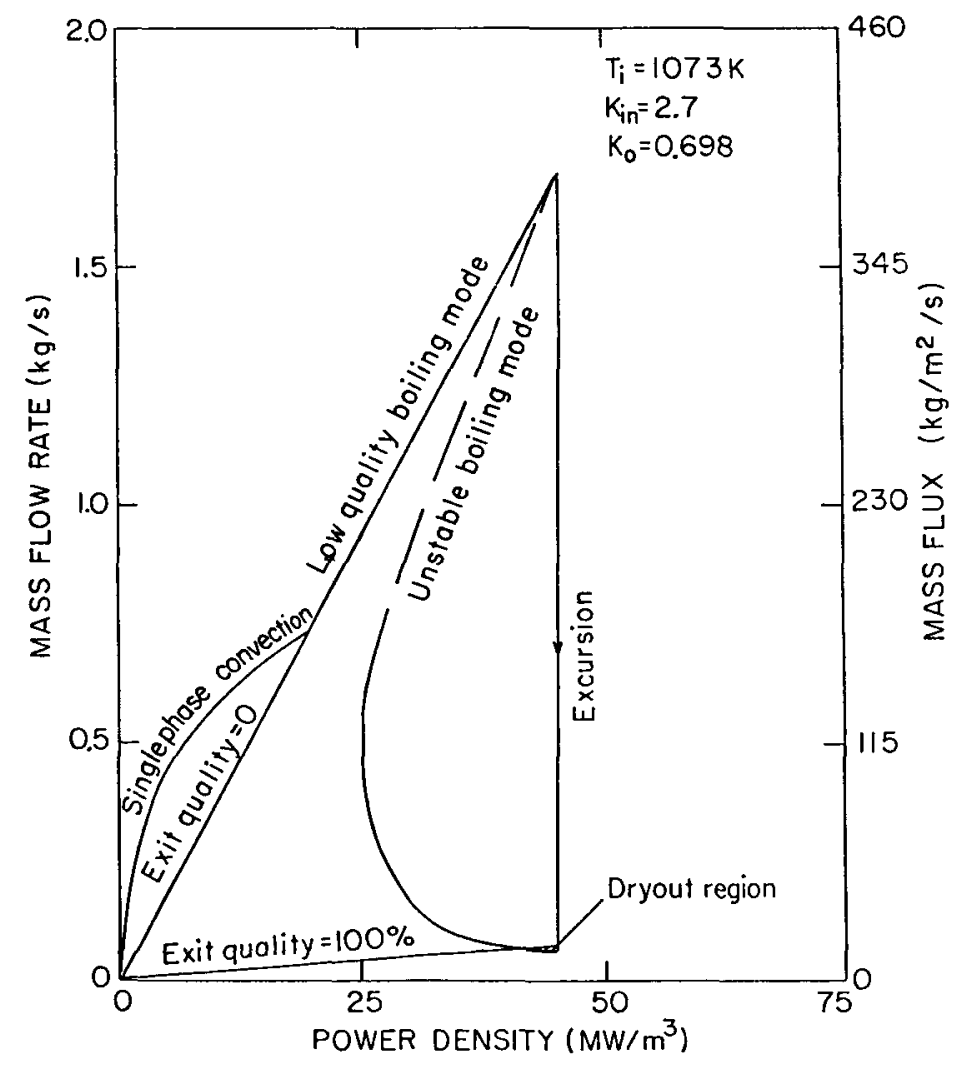

Figure 3-6 Boiling Map for CRBRP Fuel Assembly at Inlet Temperature of $1073 \mathrm{~K}$ 
Table II Gemetric Characteristics of SBT Facility

\begin{tabular}{|c|c|}
\hline \multicolumn{2}{|c|}{ Test Section } \\
\hline $\begin{array}{l}\text { I.D., m } \\
\text { Thickness, m } \\
\text { Inlet length, m } \\
\text { Heated Length, m } \\
\text { Outlet length, m } \\
\text { Hydraul ic Area, } m^{2} \\
\text { L/A, m-1 }\end{array}$ & $\begin{array}{l}3.250 \times 10^{-3} \\
2.875 \times 10^{-3} \\
3.5052 \\
0.9662 \\
1.5057 \\
8.296 \times 10^{-6} \\
7.205 \times 10^{5}\end{array}$ \\
\hline \multicolumn{2}{|c|}{ Downcomer Section } \\
\hline $\begin{array}{l}\text { I.D., m } \\
\text { Length, m } \\
\text { Hydraul ic Area, } \mathrm{m}^{2} \\
\text { L/A, } \mathrm{m}^{-1}\end{array}$ & $\begin{array}{l}51 . \times 10^{-3} \\
6.680 \\
2.043 \times 10^{-3} \\
3270\end{array}$ \\
\hline
\end{tabular}

Figures 3-7 and 3-8 show the calculated pressure drop characteristics and the boiling map corresponding to the SBT operating conditions. Table III summarizes the test results as compared to the present calculations and those predicted by the SAS3D computer code [8].

Experimentally, single-phase free convection behavior was observed for test section power densities less then $125 \mathrm{MW} / \mathrm{m}^{3}$. Due to a high degree of wall superheat (100K), a precise determination of boiling inception was not possible. To circumvent this operational problem, argon bubbles were injected upstream of the heated section to induce boiling, once boiling was established, the argon injection was terminated.

A chugging instablity was observed for test section power densities between 125 to $162 \mathrm{MW} / \mathrm{m}^{3}$. This is attributed to the high degrees of superheat and associated lack of nucleation sites $[5,12]$.

A stable boiling behavior was obseryed for periods up to 45 minutes at power densities between 162 and $200 \mathrm{MW} / \mathrm{m}^{3}$. The flow was observed to be stable in the dynamic sense but highly oscillatory. Evidence of more than one 


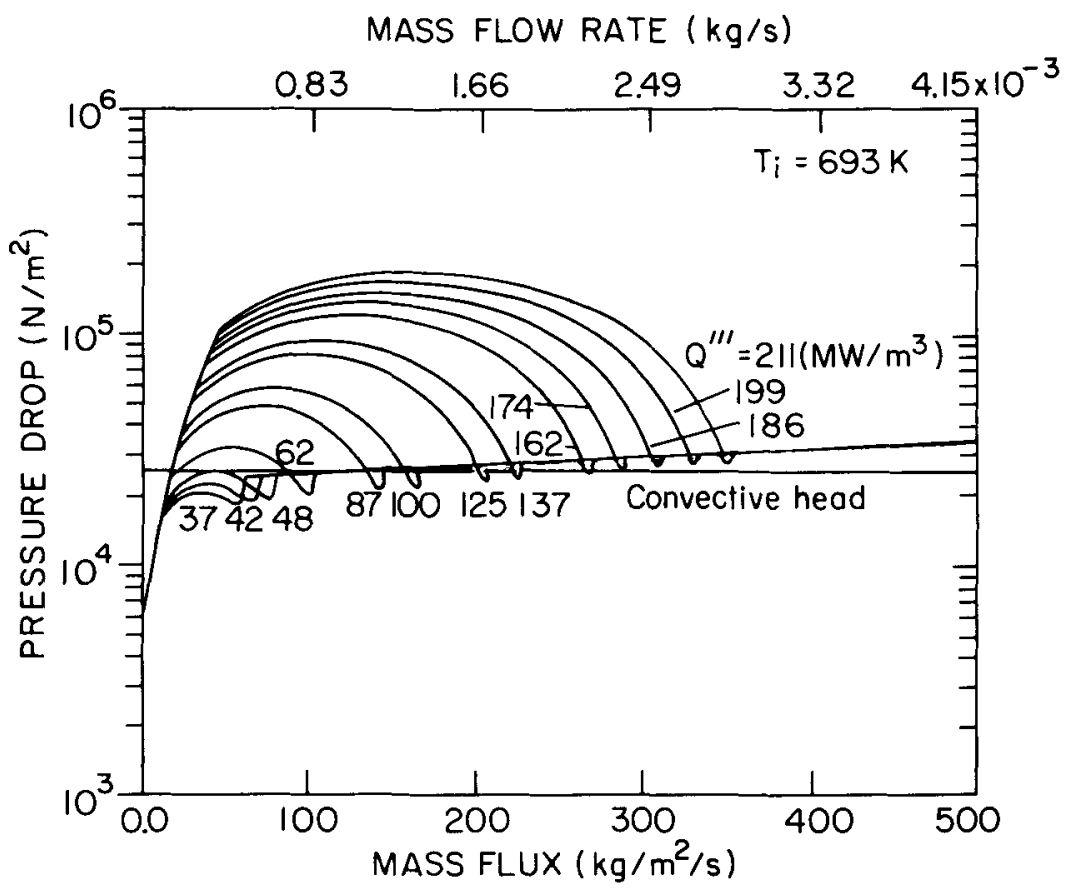

Figure 3-7 SBT Pressure Drop versus Flow at Various Power Densities

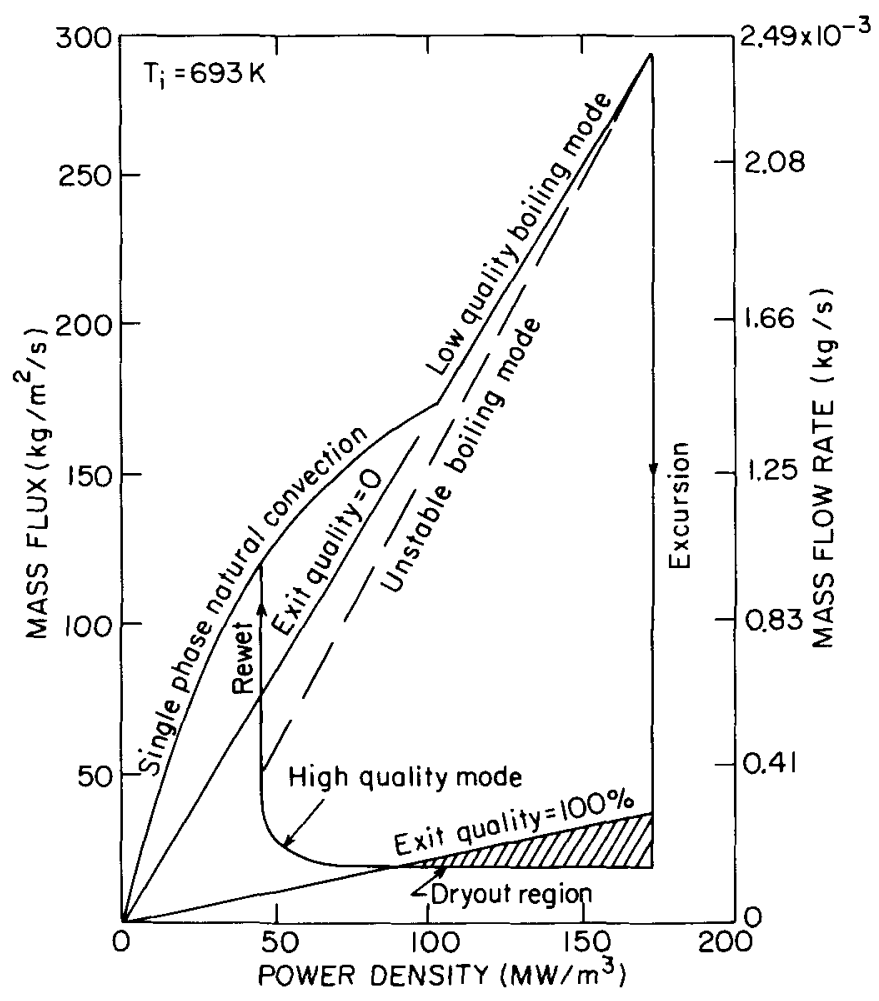

Figure 3-8 Boiling Map for ORNL Sodium Boiling Test Facility 
operating condition for the same test section power density was also observed for power densities near the lower end of the stable boiling regime.

At test section power densities above $200 \mathrm{MW} / \mathrm{m}^{3}$, intermittent dryout conditions were encountered. Recovery from dryout was frequentiy observed.

The above experimental observations are in direct agreement with analysis of the steady state model also summarized in Table I and shown in Fig. 3-7. The disagreements are in part due to the inaccuracies in the test section power measurement which are shown [5] to be about $45 \%$ at $40 \mathrm{MW} / \mathrm{m}^{3}$ and drop to around $18 \%$ at $200 \mathrm{MW} / \mathrm{m}^{3}$.

It is important to note that the SBT experiment was performed in a quasisteady-state fashion, where the test section power was increased slowly leading to natural convection boiling. Even though it is highly non-prototypic in many ways, it still demonstrates many important characteristics of low pressure boiling typical of LMFBR systems.

\subsection{Dryout Criterion}

It is evident from the computational results supported by experimental data, that enthalpy burnout is expected to take place following flow excursion for heat flux levels greater than q"dryout.

Following flow excursion, the flow rate reduces to a level corresponding to the laminar-turbulent transition regime where $C \sim 0.4$ and $n=0.25$ [19]; thus equation (2-14) becomes:

$$
q_{\text {dryout }}^{\prime \prime}\left[\frac{5 g \rho_{g}\left(\rho_{f}-\rho_{g}\right) D_{e}^{1.25}}{\mu_{g}}\right]^{0.25} \frac{A}{\pi N D L_{h}}\left(\Delta h_{s c}+h_{f g}\right)
$$


Table III SBT Natural Convection Test Results

\begin{tabular}{|c|c|c|c|c|c|c|c|c|}
\hline \multirow{2}{*}{$\begin{array}{l}\text { Test } \\
\text { Mo. }\end{array}$} & \multirow[t]{2}{*}{$\left.Q^{\prime \prime \prime}(n+1) / \pi^{3}\right)$} & \multirow{2}{*}{$\begin{array}{l}G \text { Experimental } \\
\left(\mathrm{kg} / \mathrm{m}^{2}-\mathrm{s}\right)\end{array}$} & \multicolumn{3}{|c|}{ Grediction $\left(\mathrm{kg} / \mathrm{m}^{2}-\mathrm{s}\right)$} & \multicolumn{3}{|c|}{ Comments } \\
\hline & & & Tow $x$ & unstable & high $x$ & Experimental & Present model & SAS 3D \\
\hline $107 R .2$ & 37 & 72 & 102 & -- & - & \multirow{6}{*}{$\begin{array}{l}\text { Single phase } \\
\text { liatural } \\
\text { Convection } \\
\end{array}$} & \multirow{6}{*}{$\begin{array}{l}\text { Single Pnase } \\
\text { Natural } \\
\text { Convection }\end{array}$} & \multirow{6}{*}{$\begin{array}{c}\text { Single Phas } \\
\text { Natural } \\
\text { Convection } \\
\end{array}$} \\
\hline 10981 & 42 & 205 & 113 & - & - & & & \\
\hline $108 \Omega 2$ & 62 & 93 & 136 & 86 & 21 & & & \\
\hline $100 R 3$ & 87 & 103 & 160 & 133 & 18 & & & \\
\hline $100 R 2$ & 87 & 93 & 160 & 133 & 18 & & & \\
\hline $100 R .4$ & 100 & 113 & 171 & 156.5 & 17.3 & & & \\
\hline 13121 & 125 & -- & 207.7 & 201.5 & 17.3 & \multirow{3}{*}{ Chugging } & \multirow{7}{*}{$\begin{array}{l}\text { Steady } \\
\text { Boiling }\end{array}$} & \multirow{9}{*}{$\begin{array}{l}\text { Steady } \\
\text { Boiling }\end{array}$} \\
\hline 13221 & 137 & -- & 227.5 & 222.5 & 17.3 & & & \\
\hline $130 R 1$ & 162 & 247 & 268.5 & 265.5 & 17.3 & & & \\
\hline $129 R 1$ & 162 & 103 & 268.5 & 265.5 & 17.3 & \multirow{8}{*}{$\begin{array}{l}\text { Steady } \\
\text { Boiling }\end{array}$} & & \\
\hline $121 R 1$ & 174 & 82 & 287.5 & 287.5 & 17.3 & & & \\
\hline $125 R 1$ & 174 & 93 & 287.5 & 287.5 & 17.3 & & & \\
\hline $125 R 2$ & 174 & 72 & 287.5 & 287.5 & 17.3 & & & \\
\hline $127 R 1$ & 180 & 82 & -- & -- & 17.3 & & \multirow{9}{*}{ Dryout } & \\
\hline $120 R 1$ & 186 & 247 & -- & - & 17.3 & & & \\
\hline $119 R 1$ & 199 & 113 & -- & -- & 17.3 & & & \\
\hline $126 \mathrm{R} 2$ & 199 & 93 & -- & -- & 17.3 & & & Rewet \\
\hline $122 R 1$ & 199 & -- & -- & $-\infty$ & $17 . ?$ & \multirow{5}{*}{ Dryout } & & \\
\hline $128 R 1$ & 211 & 93,31 & -- & -- & 17.3 & & & \multirow{4}{*}{ Dryout } \\
\hline $123 R .1$ & 211 & 72,41 & -- & -- & 17.3 & & & \\
\hline $124 R 1$ & 211 & -- & -- & -- & 17.3 & & & \\
\hline $126 R 1$ & 211 & -. & $\ldots$ & $=$ & 17.3 & & & \\
\hline
\end{tabular}


Table IV summarizes the calculated heat flux limits for the CRBRP fuel assembly discussed in the previous section. Also given is the approximate dryout heat flux limit determined from equation (3-1) at various inlet subcooling conditions (refer to Appendix $V$ for details).

Table IV Comparison of Heat Flux Limits

\begin{tabular}{|c|c|c|c|c|c|}
\hline$T_{\text {in }}(k)$ & $\Delta T_{s c}(k)$ & $q_{\text {Excursion }}^{\prime \prime}\left(\mathrm{w} / \mathrm{cm}^{2}\right)$ & $\begin{array}{l}q_{\text {Oryout }}^{\left(\mathrm{W} / \mathrm{cm}^{2}\right)} \\
\text { Numerical }\end{array}$ & $\begin{array}{l}q_{\text {Dryout }}^{\prime \prime}\left(\mathrm{w} / \mathrm{cm}^{2}\right) \\
\text { Eq. }(3-1)\end{array}$ & Error (\%) \\
\hline 673 & 527 & 25.7 & 7.30 & 6.4 & 14 \\
\hline 873 & 327 & 15.3 & 6.15 & 6.0 & 3 \\
\hline 1073 & 127 & 5.8 & 5.35 & 5.4 & 1 \\
\hline
\end{tabular}

It is seen that the dryout heat flux approaches the heat flux corresponding to the point of flow excursion, in the absensce of inlet subcooling. Furthermore, comparison of the detailed numerical solution with those obtained from equation (3-1) for dryout heat flux show that, the heat flux calculated from the approximate equation is conservative.

These results indicate that the decay heat may be removed via coolant boiling for decay power levels in the range of $3.7 \%$ (of nominal) at zero inlet subcooling and up to about 5\% (of nominal) at maximum inlet subcooling of $527^{\circ} \mathrm{K}$, somewhat higher than those obtained by Dunn [21] and Perkins and Bari [24] for the FFTF reactor using the SAS3D computer code.

Table $V$ lists the approximate dryout heat flux limits at various inlet subcooling conditions for the Japanese MONJU fast breeder reactor[25]. It is seen that decay heat may be removed through saturated boiling for decay power levels in the range of $7 \%$ (of average power) at zero inlet subcooling and up to about $8.5 \%$ (of average power) at maximum inlet subcooling of $530^{\circ} \mathrm{K}$.

Table $V$ Dryout Limits for MONJU Fuel Assembly

\begin{tabular}{|c|c|c|}
\hline$\Delta T_{S c}(K)$ & $q_{\text {Dryout }}^{\prime \prime}\left(\mathrm{w} / \mathrm{cm}^{2}\right)$ & $\begin{array}{ll} & \% \\
& \text { of } \\
\text { Average Heat Flux }\end{array}$ \\
\hline 530 & 9.1 & 8.5 \\
\hline 330 & 8.6 & 8.0 \\
\hline 130 & 8.1 & 7.6 \\
\hline 0 & 7.7 & 7.2 \\
\hline
\end{tabular}





\section{TRANSIENT ANALYSIS}

The analysis presented in the previous section was based on steady state or quasi-steady low heat flux natural convection conditions in LMFBRs. It was shown for the case of CRBRP, that Ledinegg instability will occur at a heat flux greater than $26 \mathrm{~W} / \mathrm{cm}^{2}$; however, any premature excursions will lead to film dryout for heat fluxes greater than $7 \mathrm{~W} / \mathrm{cm}^{2}$. It is therefore essential that the flow excursion takes place prior to the occurrence of dryout.

In order to examine the transient dependence of the Ledinegg instability and subsequent low flow operation, a transient model is developed and used to study this phenomenon.

\subsection{Conservation Equations}

The conservation of mass, momentum and energy equations in the absence of viscous dissipation for a constant area channel can be writtren as:

$$
\begin{gathered}
\frac{\partial \rho}{\partial t}+\frac{1}{A} \frac{\partial W}{\partial X}=0 \\
\frac{1}{A} \frac{\partial W}{\partial t}+\frac{1}{A^{2}} \frac{\partial}{\partial X}\left(\frac{W^{2}}{\rho^{\star}}\right)+\frac{f}{2 \rho D_{e^{A}}} W|W|+\rho g+\frac{\partial P}{\partial X}=0
\end{gathered}
$$

and

$$
\frac{\partial}{\partial t}(\rho h)+\frac{1}{A} \frac{\partial}{\partial X}(W h)=\frac{P_{h}}{A} q^{\prime \prime}
$$

The sonic effects associated with the fluid compressibility can be eliminated by assuming that fluid density may be evaluated as a function of fluid enthalpy only $[26,27]$ :

$$
\rho=\rho(h, p *)
$$

where $p *$ is a spatially average reference pressure defined as

$$
P^{*}=0.5\left(P_{\text {in }}+P_{\text {out }}\right) \text {. }
$$

The assumption of equation (4-5) is valid, because following pump failure the pressure drop across the reactor drops significantly (see Fig. 4-5), and thus can be neglected for physical property evaluation. 
Combining the mass and energy equations we obtain:

$$
\rho \frac{\partial h}{\partial t}+\left(\frac{W}{A}\right) \frac{\partial h}{\partial X}=\left(\frac{P_{h}}{A}\right) q^{\prime \prime}
$$

In order to integrate equations (4-1), (4-2) and (4-6) to determine the time dependent behavior of enthalpy and flow rates, a number of approximations are made, which will be discussed in the following subsection.

\subsection{Model Approximations}

The conservation of mass and momentum equations (Eqs. (4-1) and (4-2)) are integrated over the entire length of the channel as:

$$
\int_{0}^{L} \frac{\partial \rho}{\partial t} d x=-\frac{1}{A} \int_{0}^{L} \frac{\partial W}{\partial X} d x
$$

and

$$
\begin{aligned}
\frac{1}{A} \int_{0}^{L} \frac{\partial W}{\partial t} d X & +\frac{1}{A^{2}} \int_{0}^{L} \frac{\partial}{\partial X}\left(\frac{W^{2}}{\rho^{*}}\right) d X+\int_{0}^{L} \frac{f}{2 \rho D e^{A^{2}}} W|W| d X \\
& +\int_{0}^{L} \rho g d X+\int_{0}^{L} \frac{\partial P}{\partial X} d X=0
\end{aligned}
$$

defining :

$$
\hat{W} \equiv \frac{1}{L} \int_{0}^{L} W(x) d x
$$

and

$$
\hat{\rho} \equiv \frac{1}{L} \int_{0}^{L} \rho d x
$$

furthermore, assume the mass flow rate to be distributed according to the pre-boiling and post-boiling lengths as shown schematically in Fig. 4-1. Thus

$$
\hat{W} \simeq \frac{1}{L}\left(L_{b} W_{\text {in }}+\left(L-L_{b}\right) W_{\text {out }}\right)
$$

and,

$$
\hat{\rho} \simeq \frac{1}{L} \sum_{j=2}^{M}\left\langle\rho_{j}\right\rangle \Delta x_{j}
$$




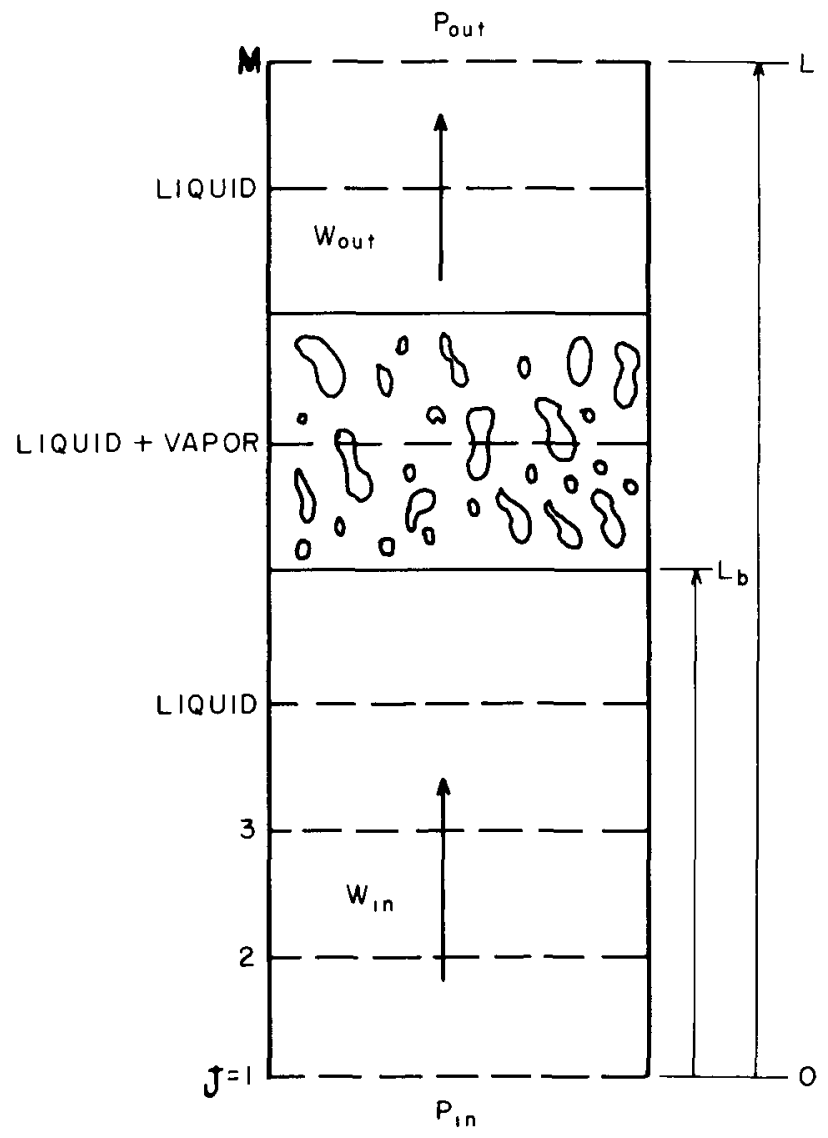

Figure 4-1 Schematics of a Boiling Channel During a Transient 
Using equations (4-11) and (4-12) and integrating equations (4-7) and (4-8) we obtain:

$$
A L \frac{d \hat{\rho}}{d t}=W_{\text {in }}-W_{\text {out }}
$$

and,

$$
\begin{aligned}
& \frac{L}{A} \frac{d W}{d t}=\left(P_{i n}-P_{\text {out }}\right)-\left(\frac{1}{\rho_{0}^{\star}}-\frac{1}{\rho_{i}}\right) \frac{\hat{W}^{2}}{A}-g \sum_{j=2}^{M}<\rho_{j}>\Delta x_{j} \\
- & \left|\frac{\hat{W}}{\hat{A}}\right| \frac{\hat{W}}{\bar{A}} \sum_{j=2}^{M} \frac{\phi_{j} f_{j} \Delta X_{j}}{2 \rho_{f} D_{e}}-\frac{1}{2}\left[\frac{K_{i n}}{\rho_{i} A_{1}}+\frac{K_{0} \phi_{0}}{\rho_{f} A_{0}}\right]|\hat{W}| \hat{W}
\end{aligned}
$$
tain:

The energy equation is integrated over a spatial increment $\Delta X_{j}$ to ob-

$$
\left\langle\rho_{j}\right\rangle A \Delta x_{j} \frac{d h_{j}}{d t}=W\left(h_{j-1}-h_{j}\right)+\bar{Q}_{j}
$$

where

$$
w=\left\{\begin{array}{lll}
W_{\text {in }} & x_{j}<0 ; & x \leq \mathrm{L}_{b} \\
W_{\text {out }} & x_{j} \geq 0 ; & x>L_{b}
\end{array}\right.
$$

The heat transfer rate is a sum of heat transfer from the cladding and the structural material to the coolant; that is

$$
\vec{Q}_{j}=h_{C j} A_{C j}\left(T_{C j}-\left\langle T_{j}\right\rangle\right)+h_{s j} A_{S j}\left(T_{S j}-\left\langle T_{j}\right\rangle\right)
$$

where $h_{c j}$ is the heat transfer coefficient of the cladding, $h_{s j}$ is the heat transfer coefficient of the structural material; $T_{C j}$ is the cladding outer surface temperature, $T_{S j}$ is the structure outer surface temperature and $\left\langle T_{j}\right\rangle$ is the nodal average coolant temperature defined as:

$$
\left\langle T_{j}\right\rangle=\frac{T_{j}+T_{j-1}}{2}
$$

where

$$
T_{j}=T\left(h_{j}\right)
$$


Note, in arriving at Eq. (4-15) it was further assumed that

$$
\frac{d h_{j}}{d t} \simeq \frac{d \bar{h}}{d t}
$$

\subsection{Numerical Integration and SSC Interface}

\subsubsection{Numerical Integration}

Equations (4-11) through (4-19) along with the heat conduction equation for the cladding and structural material are integrated numerically to obtain the thermodynamic state of the fluid in the channel as a function of time.

The integration procedure is as follows:

1. Determine $\hat{W} k+1$ as a function of $\left(P_{i n}-P_{\text {out }}\right)^{k+1}$ and $h_{j} k$ from equation (4-14) using a fifth-order predictor-corrector method of the Adams type [28].

2. Calculate the enthalpy distribution using a semi-implicit equation of the form:

$$
h_{j}^{k+1}=\frac{w^{k} h_{j-1}^{k+1}+\frac{A \Delta x_{j}}{\Delta t_{t h}}<\rho_{j}^{k}>h_{j}^{k}+\bar{Q}_{j}^{k}}{\frac{A \Delta x_{j}}{\Delta t_{t h}}<\rho_{j}^{k}>}
$$

which is explicit in $W$ and surface heat transfer rate.

3. Evaluate the boiling and nonboiling lengths as a function of enthalpy distribution and calculate $\rho$ from equation (4-4) and (4-12) with

$$
p^{*}=\frac{P_{\text {in }}+P_{\text {out }}}{2}
$$

4. Evaluate $W_{i} n^{k+1}$ and $W_{\text {out }}{ }^{k+1}$ from equations (4-11), (4-13) and using $\hat{\mathrm{k}} \mathrm{k}+1$ :

$$
\begin{aligned}
& W_{\text {in }}^{k+1}=\hat{W}^{k+1}\left(1-\frac{L_{b}}{L}\right)^{k+1} A L \frac{\hat{\rho}^{k+1}-\hat{\rho}^{k}}{\Delta t} \\
& W_{\text {out }}^{k+1}=\hat{W}^{k+1}-L_{b}^{k+1} A \frac{\hat{\rho}^{k+1}-\hat{\rho}^{k}}{\Delta t_{\text {hyd }}}
\end{aligned}
$$


Since the mass continuity and momentum equations are evaluated on a channel integral basis their integration time-step is essentially limited by the coolant transport time throughout the channel. One the other hand, the local energy equations must be integrated with a time step which is limited by the enthalpy transport in the mesh $\Delta X_{j}$ and $i t s$ value is determined based on a user supplied accuracy criterion, $\varepsilon$; that is

$$
i f\left\{\begin{array}{l}
\left|\frac{h_{j}^{k+1}-h_{j}^{k}}{h_{j}^{k}}\right| \leq \varepsilon ; \Delta t_{t h}^{k+1}=2 \Delta t_{t h}^{k} \\
\text { otherwise } ; \Delta t_{t h}^{k+1}=0.5 \Delta t_{t h}^{k}
\end{array}\right.
$$

and the thermal time step $\Delta t$ th is limited to the hydraulic time step $\Delta t_{\text {hyd }}$.

It must be noted that this integration strategy has been tested sufficiently and is adequate for the transients of interest which are slow.

\subsubsection{SSC Interface}

The present model has been interfaced with the Super System Code (SSC) [29] to provide an integrated multiassembly boiling capability for use in LMFBR system simulation studies.

The thermal-hydraulic model in SSC (Reactor Vessel) is based on the solution of the conservation equations for single-phase liquid sodium. The momentum and continuity equations are solved on the basis of non-expandable single-phase flow using the Boussinesq approximation while the coolant and fuel/structure energy equations are solved simultaneously using an efficient implicit numerical technique.

The present model uses the existing single-phase version of SSC to calculate thermal-hydraulic behavior up to the point of boiling inception, which is defined as:

$$
T_{\text {coolant }} \geq T_{\text {sat }}+\Delta T_{\text {sup }}
$$

where $T_{\text {sat }}$ is the coolant saturation temperature calculated at $\mathrm{P}^{*}$; and $\Delta \mathrm{T}_{\text {sup }}$ is a fictitious user supplied degree of superheat. ${ }^{+}$The boiling process can be suppressed by selecting a very high value for $\Delta T_{\text {sup }}$.

TThe present model assumes thermal equilibrium; and thus $\Delta T_{\text {sup }}$ is used only as a calculational flag. 
At the point of sodium boiling inception, the code automatically switches to the boiling model in the channel in which boiling is detected, and continues to use the single-phase version of the code for the remaining subcooled channels.

Figure 4-2 illustrates the flow chart for the sodium boiling calculations. The input structure for the SSC code remains unchanged; however, an option is provided to either include or ignore the thermal expansion effects in the continuity equation.

A negative sign of the $\Delta T_{\text {sup }}$ indicates that the model will be an incompressible, thermally-nonexpandable (single mass flow rate model); but a positive sign of the $\Delta T_{\text {sup }}$ indicates an incompressible, thermally expandable model.

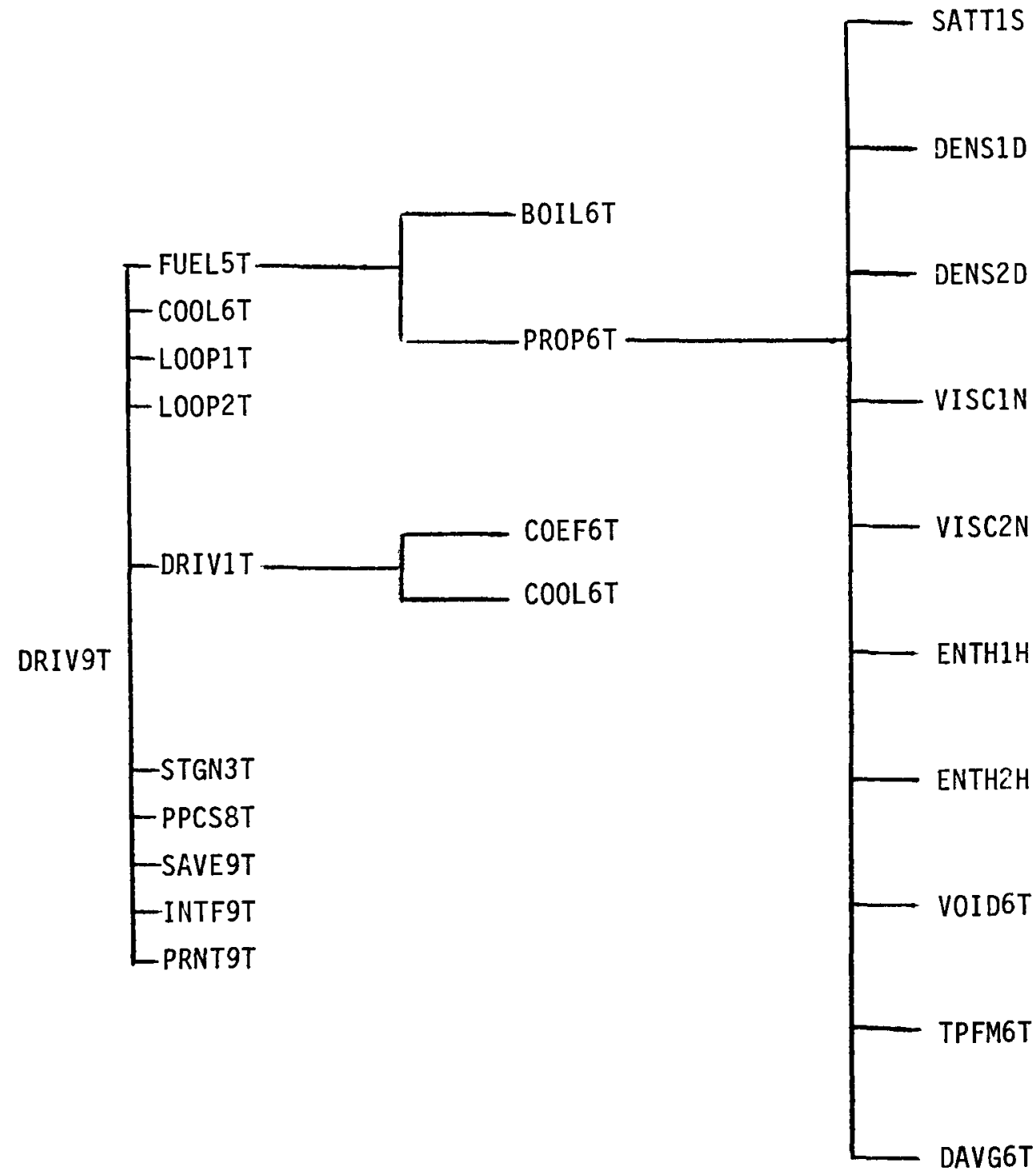

Figure 4.2 Flow Chart for SSC 


\subsection{Low Heat Flux Natural Convection Transients}

\subsubsection{Single Phase Flow}

The expected mode of decay-heat removal in most of the current LMFBR designs is via forced circulation of liquid sodium through the main coolant pumps driven by auxiliary pony motors. However, in the event of a complete loss-of-forced flow, the systems are designed to utilize thermal buoyuancy forces to provide free convection as a redundant means of decay heat removal following reactor shutdown.

Natural circulation transients can be separated into two distinct stages namely (1) the transition to natural convection flow, and (2) the establishment of natural circulation cooling. In the transition phase, the flow rates, power level, and temperatures undergo rapid changes as a function of time as a result of differing power and flow decay characteristics. Eventually, natural convection flow gets established as the power level becomes nearly constant at the decay heat level.

Figures (4-3) through (4-5) show the typical response of CRBRP to a lossof-electric power transient. Figure (4-3) illustrates that the sodium flow rate reaches its lowest value at about 60 to 90 seconds and, as the natural circulation builds up it shows a slight increase and eventually reaches a steady level as the natural circulation mode is established. It then begins to taper off, since the buoyancy head is reducing due to the slow decrease in the decay heat level. Figure (4-4) shows the temporal plots of the hot channel sodium temperatures in a fuel assembly. The sodium temperatures decrease as the reactor is scramed. The power-to-flow ratio then begins to rise around ten seconds into the transient since the power generation rate becomes essentially constant (by this time almost all of the power is due to decay heating which exhibits a slow decrease), but the sodium flow rate continues to drop. The coolant temperature, therefore, rises until it reaches a peak value when the natural circulation is established. Eventually, the sodium temperature shows a more gradual decrease due partially to slight increase in the coolant flow and to slow decrease in the heat generation rate.

Steady state analysis similar to that in Section 3 can adequately predict the established phase of natural circulation transients, but not the transition phase. Therefore, a steady state analysis can not possibly predict the peak in the coolant temperature, which sometimes may reach saturation.

\subsubsection{Two Phase Flow}

In the previous subsection, it was demonstrated that when the power to flow ratios are much larger than unity, coolant temperatures increase early in the transient and can easily reach the saturation temperature provided the decay heat level is sufficiently high. 


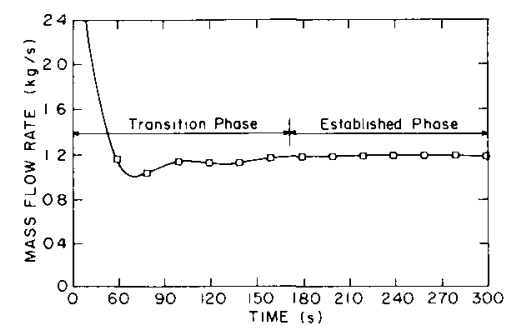

Figure 4-3 Flow Response versus Time

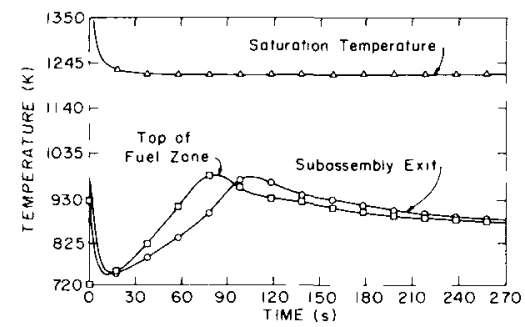

Figure 4-4 Coolant Temperatures

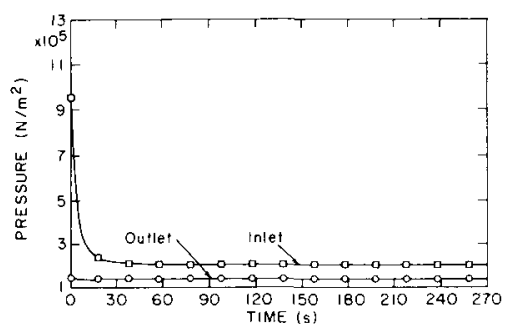

Figure 4-5 Reactor Inlet and Outlet Pressures 
To demonstrate these effects as well as the transient dependence of the flow excursion process often leading to premature excursion, loss-of-forced cooling transients in CRBRP at high power densities (larger than what exists due to decay heating following reactor shutdown) are simulated.

Figures (4-6) through (4-9) show the transient results for the decay heat level corresponding to $4.7 \mathrm{kw} / \mathrm{pin}$.

The sodium temperatures increase and reach saturation as a result of power to flow mismatch in the subassembly, leading to low quality boiling at the boundary between the fuel and upper axial blanket regions (Fig. 4-7).

The boiling region propagates upward causing a significant increase in the fluid buoyancy and thus improvement in the natural convection flow (Fig. 4-8) which will eventually sweep the two-phase front out of the assembly, thus restoring the single-phase natural convection flow. Figure 4-9 shows the sodium inlet and outlet flow rates, illustrating the flow oscillations foreseen by the steady state analysis.

Comparisons to the steady state predictions demonstrate the inadequacy of the steady state calculations in predicting sodium boiling at this power level, however the final quasi-steady natural convection flow and temperature rise was well predicted by the steady state model.

The boiling instability at this heat flux range can be demonstrated if the decay heat level is increased by a very small fraction to about $4.8 \mathrm{kw} /$ pin.

Figure 4-10 illustrates that the system undergoes a premature flow excursion causing rapid downward propagation of the voided region (Fig. 4-11) and subsequent temperature excursions (Fig. 4-12) as a result of the reduction in sodium mass flow rate and thus leading to enthalpy burnout (Fig. 4-13) also predicted by the steady state analysis.

Figure 4-10 also demonstrates that, at low heat flux, the flow excursion process is rather slow; and it occurs over a 10 to 15 second time frame, in agreement with the experimental observations reported by Costa [16].

These results testify to the degree of the transient dependence of the flow excursion process. It is seen that premature flow excursion can not be ruled out, particularly, for severe transients where the flow rate may be changing quite rapidly; however, there is a possibility of maintaining low quality oscillatory boiling for an extended period as demonstrated in recent ORNL rod bundle experiments [30].

Therefore, it can be safely assumed that permanent fuel pin dryout can be avoided prior to flow excursion. Furthermore, even if flow excursion does take place, the heat flux must be sufficiently high to cause film dryout ( $q$ " > q"Dryout).

The influence of slow heat-up of the primary system sodium, typical of loss-of-heat sink accidents with reactor scram, is being investigated to determine the extent of decay heat removal due to the high quality boiling following flow excursion (provided it occurs) prior to core uncovery. 


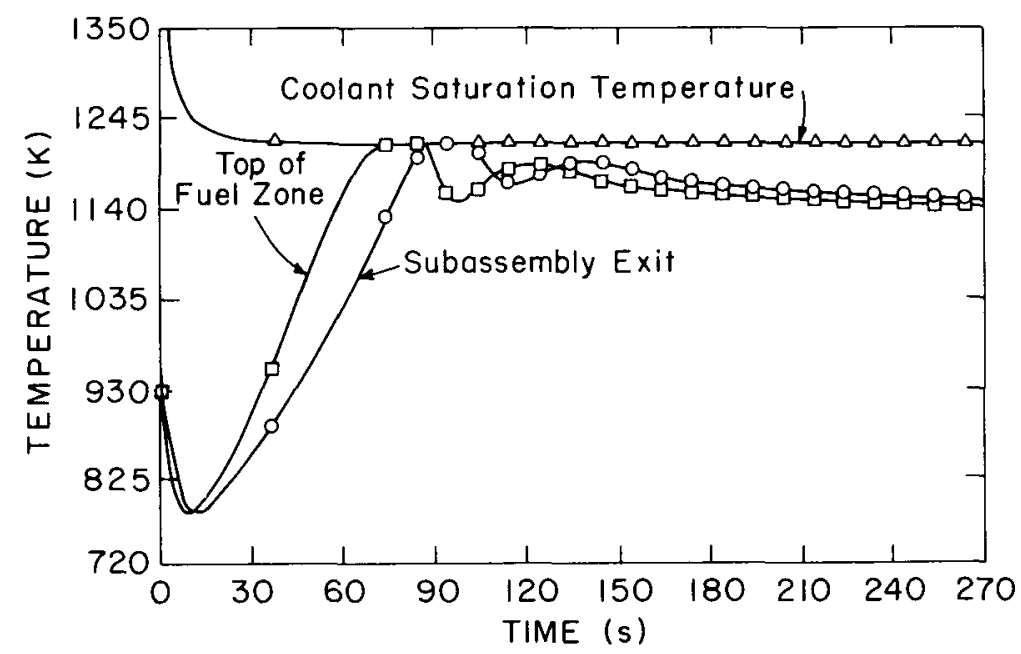

Figure 4-6 Coolant Temperatures

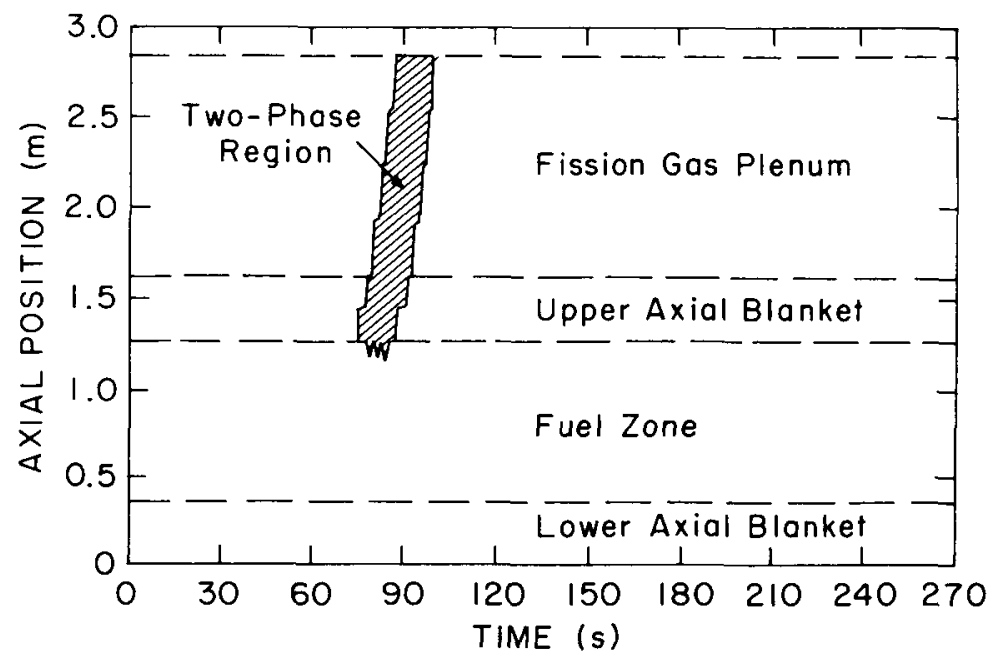

Figure 4-7 Axial Position of the Boiling Region 


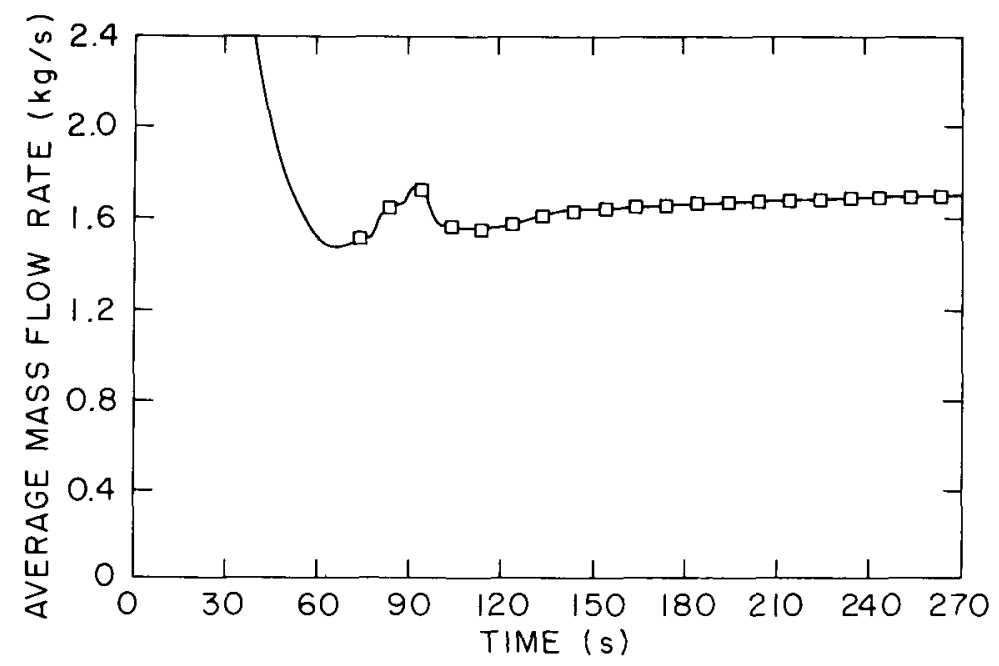

Figure 4-8 Subassembly Average Flow Rate

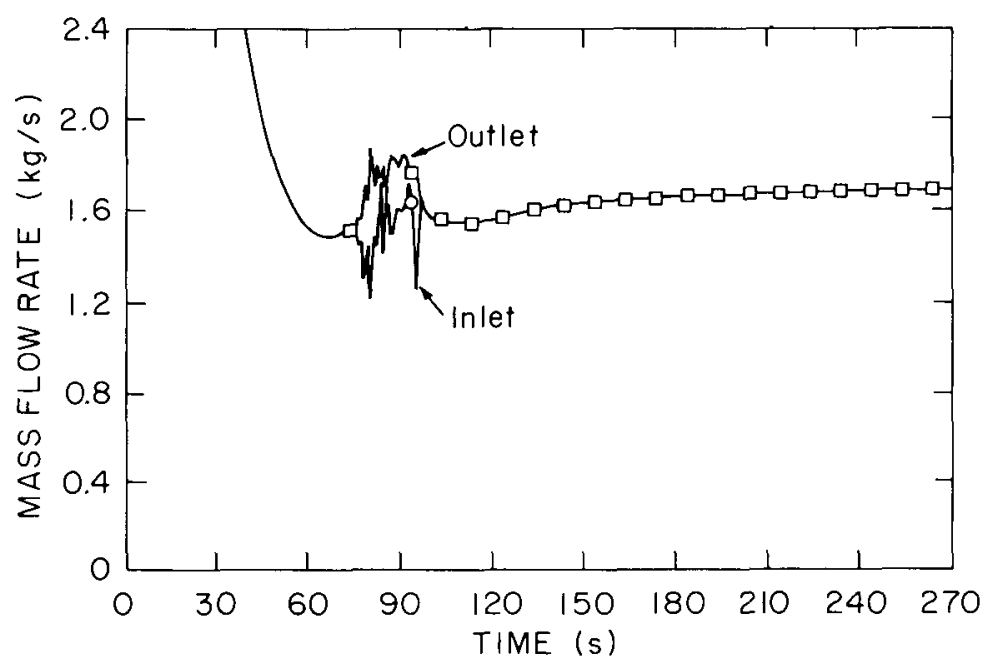

Figure 4-9 Subassembly Inlet and Outlet Flow Rates 


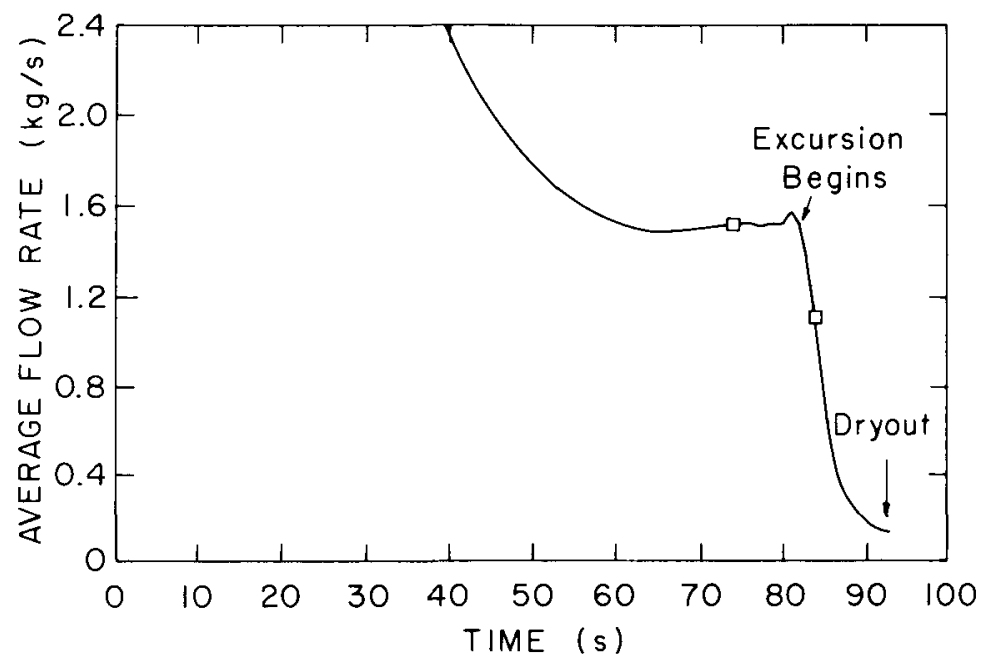

Figure 4-10 Subassemb7y Average Flow Rate

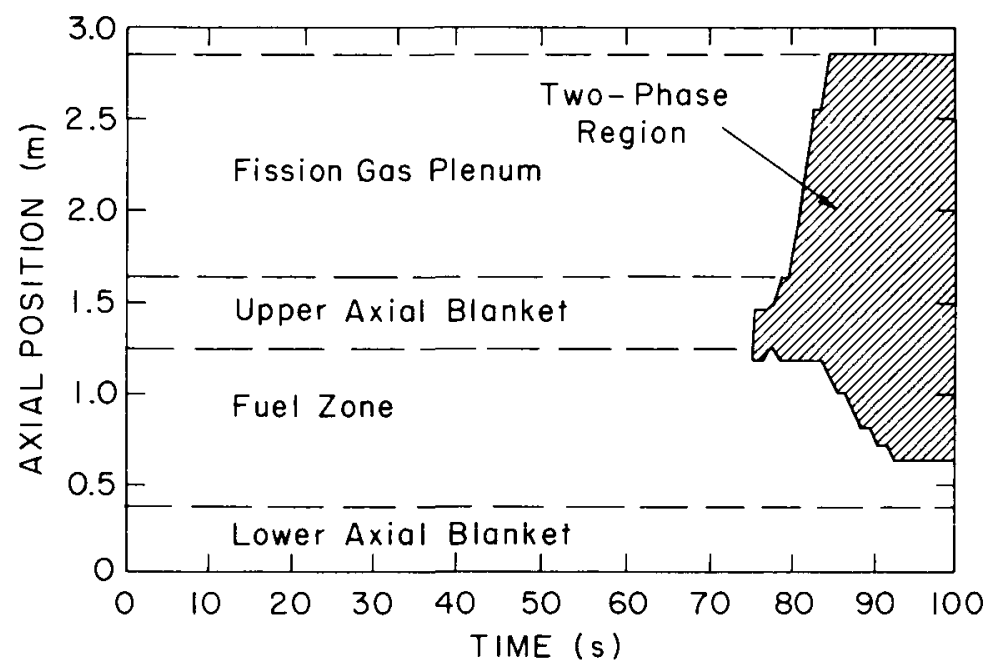

Figure 4-11 Axial Position of the Voided Region 


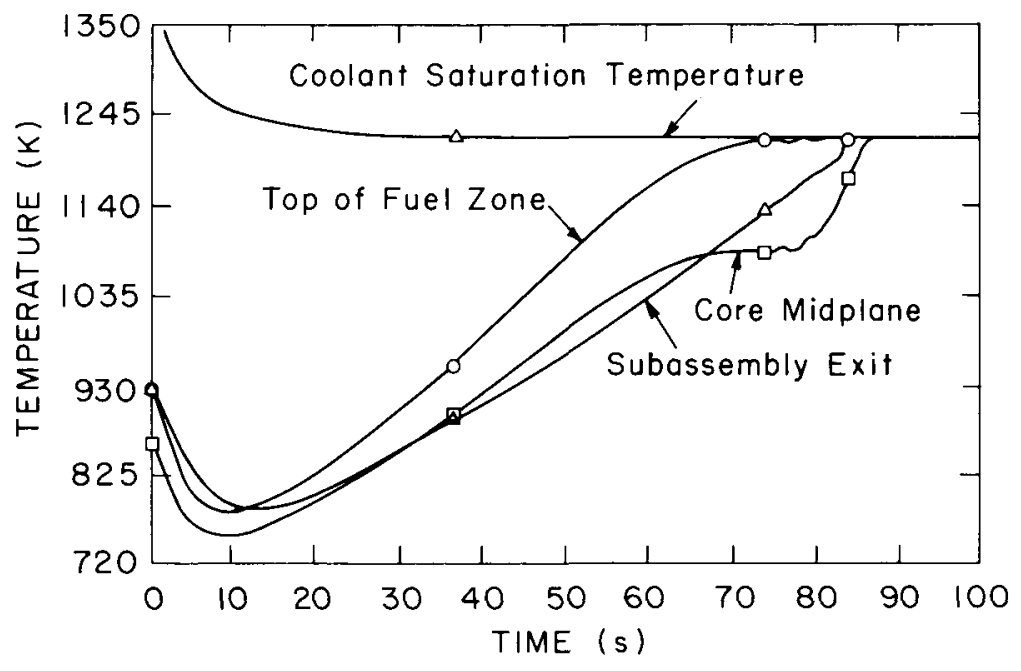

Figure 4-12 Coolant Temperatures

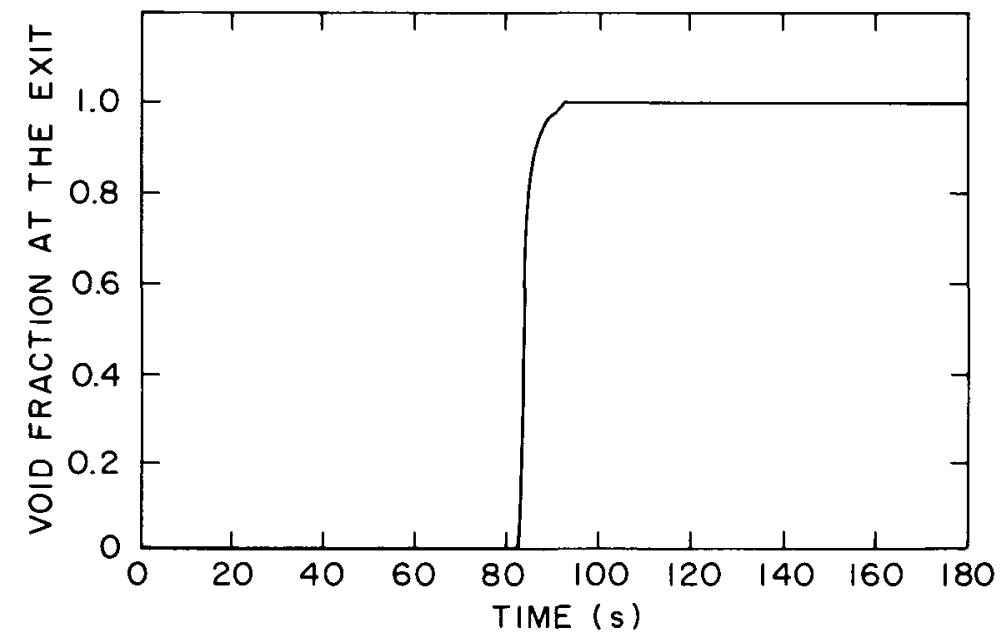

Figure 4-13 Void Fraction at the Subassembly Exit 


\subsection{High Heat Flux Boiling}

The flow excursion process for high heat flux forced circulation systems is also governed by the Ledinegg instability criterion of $\mathrm{Eq}$. (2-4), however, due to the small contribution of the thermal bouyancy head, to the total system pressure drop at high heat flux, high flow rate conditions, the unstable boiling mode is even closer to the low quality boiling mode solution. Therefore, premature excursion is much more likely as compared to the low heat flux natural convection boiling.

It has been long recognized that two-dimensional effects dominate sodium boiling process, especially in small bundles having large edge clearance $[9,10]$. However as the bundle size increases thereby reducing the edge fraction, the boiling process becomes increasingly one-dimensional. It has been demonstrated by Dearing [9], and supported by ORNL-THORS experiments, that in going from a 19 pin bundle (45\% edge) to a 217 pin bundle (21\% edge) the time to flow excursion is reduced by about a factor six.

In order to demonstrate the validity of the present model, and its applicability to typical LMFBR rod bundles at high heat flux, the model is used to simulate a loss-of-flow transient in a 217 pin bundle operating at $15 \mathrm{kw} / \mathrm{pin}$, $2 \mathrm{M} / \mathrm{S}$ sodium inlet velocity and $663 \mathrm{~K}$ sodium inlet temperature. The results are then compared with those reported by Dearing [9] using the two-dimensional Porous Blockage Code, THORAX.

Loss-of-flow is simulated by changing the driving head according to:

$$
\Delta P(t)=\left\{\begin{array}{rr}
\Delta P(t=0)[1-0.144 t] & 0 \leq t \leq 3.6 \mathrm{~s} \\
0.48 \Delta P(t=0) & t>3.6 \mathrm{~s}
\end{array}\right.
$$

Figure 4-14 shows the axial position of the voiding propagation in the bundle. It is seen that Ledinegg instability begins at the time when a large fraction of the bundle is voided leading to rapid flow excursion as illustrated by Fig. 4-15. Furthermore, film dryout is predicted to occur at about 5.5 seconds following boiling inception in excellent agreement with the twodimensional THORAX calculations.

Comparison of the flow excursion process for high and low heat flux boiling, clearly indicates that the severity of flow excursion increases with increasing power level as a result of faster propagation of the boiling region inside the bundle. Furthermore, under low heat flux natural convection boiling conditions (generally much slower than high heat flux boiling), the thermal inertia of the subassembly structural material can play a significant role in the boiling propagation. 


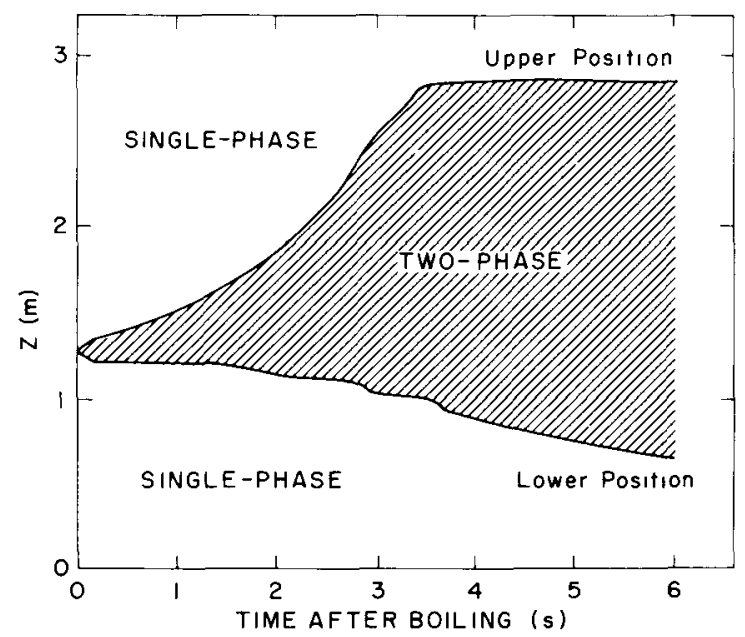

Figure 4-14 Axial Position of the Two-Phase Region Following Boiling Inception

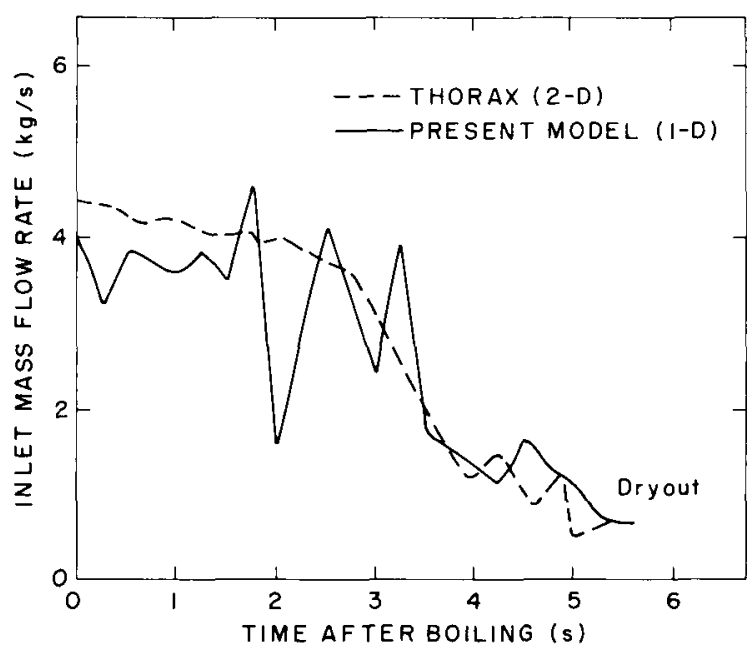

Figure 4-15 Subassembly Inlet Flow Rate Following Boiling Inception 


\subsection{Comparison of Steady State and Transient Analysis}

Table VI summarizes the features and limitations of the quasi-steady as compared to time-dependent calculations for protected loss-of-flow transients. It is evident that quasi-steady state calculations are generally adequate for moderate to slow transients; while for faster transients, especially for the transition phase to natural convection a time-dependent analysis is needed.

Table VI Comparison of Quasi-Steady and Transient Analysis

\begin{tabular}{|c|c|c|c|}
\hline \multicolumn{2}{|c|}{ Phenomenon } & Quasi-Steady Analysis & Transient Analysis \\
\hline \multirow{3}{*}{ 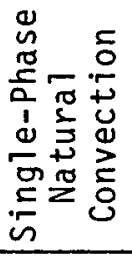 } & Transition Phase & Inadequate & Adequate \\
\hline & Established Phase & Adequate & Adequate \\
\hline & Interchannel Effects & Qualitative & Quantitative \\
\hline \multirow{4}{*}{ 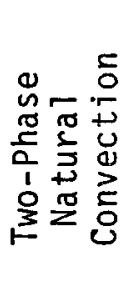 } & Flow Oscillations & Qualitative & Quantitative \\
\hline & Premature Excursion & Qualitative & Quantitative \\
\hline & Duration of Excursion & Inadequate & Adequate \\
\hline & Post Excursion Dryout & Adequate & Adequate \\
\hline
\end{tabular}




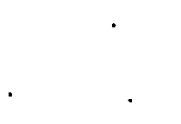




\section{SUMMARY AND CONCLUSIONS}

The low pressure sodium boiling characteristics were reviewed and physical mechanisms responsible for flow excursion phenomenon were identified.

Steady state predictions show that low quality sodium boiling is possible up to the point of Ledinegg instability leading to flow excursion and subsequent film dryout in agreement with ORNL-SBT data.

It was also demonstrated that due to the close proximity of the low quality and unstable boiling modes, premature excursions can limit extended operation up to the point of Ledinegg instability and hence lead to enthalpy burnout, provided the heat flux level is higher than that corresponding to the saturated boiling.

A flow regime-dependent approximate heat flux relationship corresponding to the limit of safe operation was presented, and comparisons with exact numerical solutions at various inlet subcooling demonstrated good agreement in the conservative direction.

A one dimensional transient computational model, based upon a three equation modified channel integral, thermally expandable model was developed and incorporated into the Super System Code (SSC). The model used the LockhartMartinelli empirical slip flow correlation, and an efficient integration procedure for analysis of low heat flux natural circulation transients in LMFBRs.

Transient calculations for low heat flux natural convection events showed that the flow excursion process is strongly transient dependent. Therefore, flow excursion induced dryout for heat flux levels greater than saturated low flow convection heat flux can not be ruled out.

Analysis of a high heat flux forced convection, loss-of-flow transient for a 217 pin rod bundle showed a significantly faster flow excursion leading to fuel pin dryout in excellent agreement with parallel calculational results using the experimentally validated two-dimensional THORAX code.

Premature flow excursion may preclude operation up to the limit of Ledinegg instability. However, if sodium boiling could be avoided in the first minutes after reactor scram, subsequent boiling could remove sufficient decay heat to prevent cladding failure provided core uncovery has not taken place; this is in agreement with studies concluded recently $[21,22]$. Furthermore, the inclusion of the flow regime dependence on the dryout heat fluxes proposed in this report significantly influences the accurate prediction of the safe heat flux limits. 


\section{REFERENCES}

1. M. Khatib-Rahbar, J. G. Guppy, and A. K. Agrawal, "Hypothetical Loss-ofHeat-Sink and In-Vessel Natural Convection: Homogeneous and Heterogeneous Core Designs", in Decay Heat Removal and Natural Convection in Fast Breeder Reactors, A. K. Agrawal and J. G. Guppy (Ed.), Hemisphere Publishing Co. (1981).

2. W. D. Ford, "Bubble Growth and Collapse in Narrow Tubes with Nonuniform Temperature Profiles", Argonne National Laboratory, ANL-7746 (1970).

3. F. E. Dunn et. al., "The SAS2A LMFBR Accident Analysis Computer Code", Argonne National Laboratory, ANL/RAS 73-39, (1973).

4. W. D. Hinkle, "Water Tests for Determining Post Voiding Behavior in the LMFBR", Massachusetts Institute of Technology, Energy Laboratory, MIT-EL76-005 (1976).

5. P. W. Garrison, R. H. Morris, and B. H. Montgomery, "Dryout Measurements for Sodium Natural Convection in a Vertical Channel", Oak Ridge National Laboratory, ORNL/TM-7018 (1979).

6. R. J. Ribando et. al., "Sodium Boiling in a Full-Length 19-Pin simulated Fuel Assembly (THORS Bundle 6A)", Oak Ridge National Laboratory, ORNL/TM6553 (1979).

7. A. E. Levin and P. Griffith, "Development of a Model to Predict Flow 0scillations in Low-Flow Sodium Boiling", Massachusetts Institute of Technology, Energy Laboratory, MIT-EL-80-006 (1980).

8. G. Klein and F. Dunn, "SAS3D Analys is of Natural-Convection Boiling Behavior in the Sodium Boiling Test Facility", Trans. Am. Nucl. Soc. 33,517 (1979).

9. J. F. Dearing, "Two-Dimensional Computational Modeling of Sodium Boiling in Simulated LMFBR Fuel Pin Bundles", Trans. Am. Nucl. Soc. $\underline{38}, 755$, (1981).

10. A. L. Schor and N. E. Todreas, "A Four Equation Two-Phase Flow Model for Sodium Boiling Simulation of LMFBR Fuel Assemblies", Proceeding of 10th Liquid Metal Boiling Working Group, H.M. Kottowski and W. Peppler (Eds.), Karlsruhe, Federal Republic of Germany (1982)

11. R. T. Lahey, Jr., "The Analysis of System Pressure Drop Characteristics During Flow Boiling", Trans. Am. Nucl. Soc. 38, 770 (1981).

12. J. A. Bour'e et. al., "Review of Two-Phase Flow Instabilities", Nucl. Eng. and Design 25, 165 (1973).

13. G. Yadigaroglu, "Two-Phase Flow Instabilities and Propagation Phenomena", in Thermohydraulics of Two-Phase Systems for Industrial Design and Nuclear Engineering, J. M. Delhaye, M. Giot, and M. L. RiethmulTer (Eds.), Hemisphere PubTishing Co. (1981). 
14. J. G. Collier, Convective Boiling and Condensation, McGraw-Hill Book Co., UK, (1972).

15. D. Butterworth, "A Comparison of Some Void-Fraction Relationships for CoCurrent Gas-Liquid Flow", Int. J. of Multiphase Flow, 1, 845 (1975).

16. J. Costa, "Contribution to the Study of Sodium Boiling During Slow Pump Coastdown in LMFBR Subassemblies", in Symposium on the Thermal and Hydraulic Aspects of Nuclear Reactor Safety VoT. 2, 0. C. Jones, Jr., and S. G. Bankoff (Eds.), ASME, New York (1978).

17. S. L. Additon and E. A. Parziale, "Natural Circulation in FFTF, A LoopType LMFBR", in Symposium on the Thermal and Hydraulic Aspects of Nuclear Reactor Safety, Vol. 2, 0. C. Jones, Jr. and S. G. Bankoff, (Eds.), ASME, New York (1977).

18. E. H. Novendstren, "Turbulent Flow Pressure Drop Model for Fuel Rod Assemblies Utilizing a Helical Wire-Wrap Space System", Nucl. Eng. \& Design 22, 19 (1972).

19. D. R. Spencer and R. A. Markley, "Friction Factor Correlation for 217-Pin Wire-Wrap-Spaced LMFBR Fuel Assemblies", Trans. Am. Nucl. Soc. 39, 1014 (1981).

20. A. K. Agrawal, M. Khatib-Rahbar, and I. K. Madni, "Prediction of Decay Heat Removal Capabilities for LMFBRs and Comparison with Experiments", Nucl. Eng. Design $\underline{66}, 437$ (1981).

21. F. E. Dunn, "Severe FFTF Natural Ciurculation Transients with Boiling", ANL/RAS 76-26 (Sept. 1976).

22. H. K. Fauske and M. Ishii, "Sodium Re-entry and Dryout Criteria Under Decay Power Conditions", Proceedings of the International Meeting on Liquid Metal Fast Breeder Reactor Safety and Related Design and Operational Aspects, Lyon-Ecully, France, July 19-23, 1982.

23. Clinch River Breeder Reactor Plant, Preliminary Safety Analysis Report, Project Management Corporation (1975).

24. K. R. Perkins and R. A. Bari, "SAS-3D Evaluation of Boiling at Decay-Heat Levels in FFTF", Trans. Am. Nucl. Soc. 33, 516 (1979).

25. A. Watanabe, "MONJU Description", Private Communication, Power Reactor and Nuclear Fuel Development Corporation, Tokyo, Japan (1981).

26. J. E. Meyer, "Hydrodynamic Models for the Treatment of Reactor Thermal Transients", Nucl. Sci. and Eng. 10, 269 (1961).

27. J. E. Meyer, and R. P. Rose, "Application of a Momentum Integral Model to the Study of Parallel Channel Boiling Flow 0scillations", ASME Journal of Heat Transfer, 85, (1963). 
28. F. T. Krogh, "Variable Order Integrators for the Numerical Solution of Ordinary Differential Equations", Jet Propulsion Laboratory Report (May 1, 1969).

29. A. K. Agrawal, et al., "An Advanced Thermohydraulic Simulation Code for Transients in LMFBR's (SSC-L-Code)", Brookhaven National Laboratory, BNL-NUREG-50773 (1978).

30. S. D. Rose, et al., "Analysis of Natural Convection Sodium Boiling in a 61-Pin Simulated LMFBR Fuel Assembly", Proceedings of 10th Liquid Metal Boiling Working Group, H.M. Kottowski and W. Peppler (Eds.), Karlsruhe, Federal Republic of Germany (1982).

31. F. C. Engel, R. A. Markley, and A. Bishop, "Laminar Transition and Turbulent Parallel Flow Pressure Drop Across Wire-Wrap-Spaced Rod Bundles", Nucl. Sci. Eng. 69, 290 (1979), see also Nucl. Sci. Eng. 74, 226 (1980). 


\section{APPENDIX I}

\section{DEFINITION OF AVERAGE DENSITY}

Remembering that the fluid density is assumed to be a function of enthalpy only, and assuming that enthalpy varies linearly with position within the nodal volume bounded by $X_{j}$ and $\left(X_{j}+\Delta X_{j}\right.$, thus the nodal average density becomes

$$
\left\langle\rho_{j}\right\rangle=\frac{1}{h_{j}-h_{j-1}} \int_{h_{j-1}}^{h_{j}} \rho d h
$$

which can be integrated to obtain:

$$
<\rho_{j}>= \begin{cases}0.5\left(\rho_{j}+\rho_{j-1}\right) & h_{j-1} \leq h_{j}<h_{f} \\ 0.5 \kappa_{j}\left(\rho_{j-1}+\rho_{f}\right)+\left(1-k_{j}\right) \frac{\ln \left(\rho_{f} / \rho_{j}\right)}{\left(\frac{1}{\rho_{j}}-\frac{1}{\rho_{f}}\right)} & h_{j-1} \leq h_{f}<h_{j} \\ \frac{\ln \left(\rho_{j-1} / \rho_{j}\right)}{\left(\frac{1}{\rho_{j}}-\frac{1}{\rho_{j-1}}\right)} & h_{f}<h_{j-1}<h_{j}\end{cases}
$$

where

$$
k_{j} \equiv \frac{h_{f}-h_{j-1}}{h_{j}-h_{j-1}}
$$

$h_{f}$ is the enthalpy of saturated liquid at reference pressure ${ }^{* *}$. The two-phase density is defined as:

$$
\rho_{j}=\left(1-\alpha_{j}\right) \rho_{f}+\alpha_{j} \rho_{g} \quad 0 \leq x_{j} \leq 1
$$

and the thermodynamic quality is given by

$$
x_{j}=\left(h_{j}-h_{f}\right) / h_{f g}
$$


The momentum averaged "apparent density", $\rho_{j}^{*}$ is defined as:

$$
\rho_{j}^{*}=\left(\frac{x_{j}^{2}}{\alpha_{j}} v_{g}+\frac{\left(1-x_{j}\right)^{2}}{\left(1-\alpha_{j}\right)} v_{f}\right)^{-1}
$$

where $\hat{v}_{g}$ and $\hat{v}_{f}$ are the specific volume of saturated vapor and liquid respectively. 


\section{APPENDIX II}

\section{FRICTION FACTOR CORRELATIONS}

The friction factor $f$ is calculated using an empirical (based on steady state measurements) correlation of the form:

$$
f=C \operatorname{Re}^{-n}
$$

where $C$ and $n$ are flow and geometry dependent parameters defined in the following sections.

\section{II.1 Fuel Assemblies}

The friction factor for wire-wrapped 217 pin rod bundle has been measured by Spencer and Markley [19]. The correlation is characterized by smooth transition from laminar to turbulent flow as:

$$
\begin{array}{ll}
f=\frac{84}{\operatorname{Re}} & \operatorname{Re} \leq 800 \\
f=\left(1.078+0.3 \times 106 / \operatorname{Re}^{2}\right) f_{C} & \operatorname{Re}>800
\end{array}
$$

where the Colbrook friction factor is defined by the implicit equation:

$$
1 / f_{C}=-2 \log \left[2.51 / \operatorname{Re} f_{C}\right]
$$

Equation (II 3) and its first derivative are continuous throughout the transition regime.

The transcendental form of equation (II-4) requires an iterative solution. To resolve this inconvenience, as approximate correlation based upon Blasius relation is used as follows:

$$
f=0.316 M_{F} R^{-0.25} \quad \operatorname{Re} \geq 800
$$

where the multiplier $M_{F}$ is correlated as:

$$
M_{F}=1.029+2837 \mathrm{Re}^{-1.24}
$$


Equation (II-5) is continuous throughout the transition regime; however, the first derivative is not continuous at Reynolds number of 800 .

\section{II.2 Blanket Assemblies}

The friction factor for the blanket assemblies is correlated by Engle et. a1., [31] as:

$$
f=\left\{\begin{array}{lr}
\frac{110}{\operatorname{Re}} & \operatorname{Re}<400 \\
\frac{110}{\operatorname{Re}} \sqrt{1-\psi}+\frac{0.48}{\operatorname{Re}^{0.25}} \sqrt{\psi} & 400 \leq \operatorname{Re} \leq 5000 \\
0.48 \operatorname{Re}^{-0.25} & \operatorname{Re}>5000
\end{array}\right.
$$

where the intermittency factor $\psi$ is defined as

$$
\psi=(\operatorname{Re}-400) / 4600
$$

Note that the expression for the turbulent regime has 0.48 in the numerator as corrected by the authors.

\section{A. 3 Control Assemblies}

The friction factor for the control assemblies is calculated using the Novendstern [18] correlation,

$$
f=M_{C} 0.316 R e^{-0.25}
$$

where

$$
M_{C}=\left[\frac{1.034}{(P / D)^{0.124}}+\frac{29.7(P / D)^{6.94} \mathrm{Re}^{0.086}}{(H / D)^{2.239}}\right]^{0.885}
$$

where $P$ is the pitch and $H$ is the wire-wrap lead.

The friction factor for circular tubes such as the ORNL-SBT test section is calculated using equation (II-1) with $C=0.316$ and $n=0.25$. 
The steady state energy and momentum equations (2-5) and (2-6) can be recasted to the following form:

$$
\left(N \pi D L_{h}\right) q^{\prime \prime}=W \Delta h
$$

and

$$
\frac{1}{2} \frac{W^{2}}{\rho_{0}}\left(\frac{f L}{D_{e} A^{2}}\right)+g \Delta \rho L=0
$$

where the spatial acceleration term and losses due to inlet and outlet have been neglected.

For single-phase liquid,

$$
\Delta h=C_{p} \Delta T
$$

and

$$
\Delta \rho=-\rho_{0} \quad B \Delta T
$$

Here $\rho_{0}$ is the reference cold leg density and $\beta$ is the volume coefficient of thermal expansion $\left(K^{-1}\right)$. Inherent in equation (III-4) is the assumption that sodium density is a linear function of temperature.

Substituting equations (III-3) and (III-4) into equations (III-1) and (III-2) one obtains:

$$
\Delta T=\frac{N_{\pi} D L_{h}}{C_{p}}\left(\frac{q^{\prime \prime}}{W}\right)
$$

and

$$
\left(\frac{1}{2 \rho_{0}} \frac{f L}{D e^{A^{2}}}\right) \quad W^{2}-g \rho_{0} \beta \Delta T L=0
$$


Therefore:

$$
\left(\frac{1}{2 \rho_{0}} \frac{f L}{D_{e} A^{2}}\right) W^{2}-g \rho_{0} \beta L \quad\left(\frac{N \pi D L_{h}}{C_{p}}\right) \quad \frac{q^{\prime \prime}}{W}=0
$$

The wall friction factor can be represented by the Darcy-Weisbach relation of the form:

$$
f=C R e^{-n}
$$

or

$$
f=c\left(\frac{W D_{e}}{\mu A}\right)^{-n}
$$

Substituting equation (III-9) into (III-7) and solving for the characteristic natural convection flow, one obtains:

$$
W=\left[\frac{2 g \beta \rho_{0}^{2} P_{h} L_{h} D e^{n+1}}{C C_{p} A^{n-2} \mu^{n}}\right]^{1 /(3-n)} \quad q^{1 /(3-n)}
$$

and when Equation (III-10) is back substituted into equation (III-1) yields the channel enthalpy rise,

$$
\Delta h=\left[\frac{C C_{P} \mu^{n}\left(P_{h} L_{h}\right)^{2-n}}{2 g \beta \rho_{0}^{2} A^{2-n} D e^{n+1}}\right]^{1 /(3-n)} q^{\prime \prime(2-n) /(3-n)}
$$

or alternatively, the coolant temperature rise,

$$
\Delta T=\left[\frac{C C_{P}^{n-2} \mu^{n}\left(P_{h} L_{h}\right)^{2-n}}{2 g \beta \rho_{0}{ }^{2} A^{2-n} D e^{n+1}}\right]^{1 /(3-n)} q^{\prime \prime(2-n) /(3-n)}
$$


The intersection of the saturated vapor line $\left(x_{0}=100 \%\right)$ and the high quality stable boiling mode solution can be obtained as:

$$
\left(P_{h} L_{h}\right) q^{\prime \prime}=W\left(\Delta h_{S C}+h_{f g}\right)
$$

and

$$
\frac{1}{2} \frac{W^{2}}{\rho_{g}}\left(\frac{f_{g} L}{D e A^{2}}\right)-g\left(\rho_{f}-\rho_{g}\right) L=0
$$

Inherent in equation (IV-2) are the assumptions that the sodium at the inlet is at saturation; and the wall friction is represented by the singlephase sodium vapor of the form:

$$
f_{g}=C \operatorname{Reg}^{-n}
$$

Equation (IV-3) can be substituted into Equation (IV-2) to get:

$$
\frac{L}{2 \rho_{g} D e A^{2}} C\left(\frac{W D e}{A \mu_{g}}\right)^{-n} \quad W^{2}=g\left(\rho_{f}-\rho_{g}\right) L
$$

or,

$$
W=\rho_{g} A\left[\frac{2 g\left(\rho_{f}-\rho_{g}\right) D e^{1+n}}{c_{\mu g}^{n} \rho_{g}^{1-n}}\right]^{1 /(2-n)}
$$

and thus the heat flux relation can be determined from Equation (IV-1) as:

$$
q^{\prime \prime}=\left[\frac{2 g \rho_{g}\left(\rho_{f}-\rho_{g}\right) D e^{1+n}}{C \mu_{g}^{n}}\right]^{1 /(2-n)} \frac{A}{P_{h} L_{h}}\left(\Delta h_{s c}+h_{f g}\right)
$$




\section{APPENDIX $V$ \\ DRYOUT HEAT FLUX CALCULATIONS}

The fluid thermodynamic properties are evaluated based upon the average pressure defined in Equation (4-5) and shown in Fig. (4-3) as:

$$
P^{*}=0.5\left(P_{\text {in }}+P_{\text {out }}\right)
$$

The following functional fits [29] are used to determine the required thermophysical properties:

Saturation Temperature ( $K$ )

$$
T_{S}=\frac{12130.0}{10.51-\ln \left(9.869 \times 10^{-6} p^{*}\right)}
$$

Density of Saturated Liquid $\left(\mathrm{kg} / \mathrm{m}^{3}\right)$

$$
\begin{gathered}
370.9 \leq T_{S} \leq 1644.2 \\
\rho_{f}=1011.597-0.22051 \mathrm{~T}_{S}-1.92243 \times 10^{-5} \mathrm{~T}_{\mathrm{S}}^{2} \\
+5.63769 \times 10^{-9} \mathrm{~T}_{\mathrm{S}}^{3}
\end{gathered}
$$

Density of Saturated Vapor $\left(\mathrm{kg} / \mathrm{m}^{3}\right)$

$$
\rho_{g}=\frac{3.27317 \times 10^{-3}-8.72393 \times 10^{-7} T_{S}+6.07353 \times 10^{-10} T_{S}{ }^{2}}{T_{S}} p *
$$

Enthalpy of Saturated Liquid $(\mathrm{J} / \mathrm{kg})$

$$
h_{f}=-6.7511 \times 10^{4}+1630.22 T_{s}-0.41674 T_{s}^{2}+1.54279 \times 10^{-4} T_{s}^{3}
$$


Enthalpy of Vaporization $(\mathrm{J} / \mathrm{kg})$

$$
\begin{gathered}
1150 \leq \mathrm{T}_{\mathrm{S}} \leq 1500 \mathrm{~K} \\
\mathrm{~h}_{\mathrm{fg}}=4.40241 \times 10^{6}-17.5055 \mathrm{~T}_{\mathrm{s}}-0.380184 \mathrm{~T}_{\mathrm{s}}^{2}
\end{gathered}
$$

Dynamic Viscosity of Saturated Vapor (NS/m²)

$$
\mu_{g}=9.44 \times 10^{-6}+1.14 \times 10^{-8} \mathrm{~T}_{\mathrm{S}}
$$

Using Eq. (3-1):

$$
q_{\text {Dryout }}^{\prime \prime} \geq\left[\frac{5 g \rho_{g}\left(\rho_{f}-\rho_{g}\right) D_{e}^{1.25}}{\mu_{g}^{0.25}}\right]^{0.57} \frac{A}{\pi N D L_{h}}\left(\Delta h_{s c}+h_{f g}\right)
$$

Clinch River Breeder Reactor Fuel Assembly [23]

$$
\begin{aligned}
& N=217 \text { pins/assembly } \\
& p *=1.5 \times 10^{5} \mathrm{~N} / \mathrm{M}^{2} \\
& D_{e}=3.25 \times 10^{-3} \mathrm{~m} \\
& T_{S}=1199 \mathrm{~K} \\
& D=4.9148 \times 10^{-3} \mathrm{~m} \\
& \rho_{f}=729.3 \mathrm{~kg} / \mathrm{m}^{3} \\
& L_{h}=1.626 \mathrm{~m} \\
& A=4.335 \times 10^{-3} \mathrm{~m}^{2} \\
& \rho_{g}=0.388 \mathrm{~kg} / \mathrm{m}^{3} \\
& g=9.81 \mathrm{~m} / \mathrm{s}^{2} \\
& h_{f}=1.554 \times 10^{6} \mathrm{~J} / \mathrm{kg} \\
& h_{f g}=3.835 \times 10^{6} \mathrm{k} / \mathrm{kg} \\
& \mu_{g}=2.31 \times 10^{-5}\left(\mathrm{NS} / \mathrm{m}^{2}\right)
\end{aligned}
$$

Therefore,

$$
q_{\text {Dryout }}^{\prime \prime} \geq 0.0141\left(\Delta h_{s c}+h_{f g}\right) W / m^{2}
$$

or

$$
q_{\text {Dryout }}^{\prime \prime} \geq 1.410 \times 10^{-6}\left(\Delta h_{\mathrm{Sc}}+h_{f g}\right) \mathrm{W} / \mathrm{cm}^{2}
$$


MONJU Fuel Assembly [25]

$$
\begin{aligned}
& N=169 \text { pins/assembly } \\
& D_{e}=3.23 \times 10^{-3} \mathrm{~m} \\
& D=6.5 \times 10^{-3} \mathrm{~m} \\
& L_{h}=0.930 \mathrm{~m} \\
& A=3.66 \times 10^{-3} \mathrm{~m}^{2}
\end{aligned}
$$

Therefore,

$$
q_{\text {Dryout }}^{\prime \prime} \geq 0.0201\left(\Delta h_{s c}+h_{f g}\right) w / m^{2}
$$

or

$$
q_{\text {Dryout }}^{\prime \prime} \geq 2.01 \times 10^{-6}\left(\Delta h_{s c}+h_{f g}\right) \quad W / \mathrm{cm}^{2}
$$

